Illinois State University

ISU ReD: Research and eData

Theses and Dissertations

6-17-2021

\title{
The Impact of an Inclusive Curriculum on Attitudes Toward Sexual Minority Populations
}

Kirstin Kaylene Johnson

Illinois State University, kkjohns@ilstu.edu

Follow this and additional works at: https://ir.library.illinoisstate.edu/etd

\section{Recommended Citation}

Johnson, Kirstin Kaylene, "The Impact of an Inclusive Curriculum on Attitudes Toward Sexual Minority Populations" (2021). Theses and Dissertations. 1444.

https://ir.library.illinoisstate.edu/etd/1444

This Dissertation is brought to you for free and open access by ISU ReD: Research and eData. It has been accepted for inclusion in Theses and Dissertations by an authorized administrator of ISU ReD: Research and eData. For more information, please contact ISUReD@ilstu.edu. 


\section{THE IMPACT OF AN INCLUSIVE CURRICULUM ON ATTITUDES TOWARD SEXUAL MINORITY POPULATIONS}

\section{KIRSTIN K. JOHNSON}

69 Pages

The current study examined changes in heterosexual individuals' attitudes toward sexual minority populations when exposed to inclusive curriculum materials. Participants were randomly assigned to receive one of two sets of curriculum materials (i.e., inclusive or noninclusive). Inclusive materials provided representation of sexual minority individuals, whereas the non-inclusive materials provided representation of only heterosexual individuals. Participants completed a survey that included measures of attitudes toward sexual minority individuals before and after exposure to the curriculum. Hypotheses that individuals exposed to inclusive curriculum would have improved attitudes towards sexual minority individuals from pre-test to post-test were not supported. The hypothesis that several factors would moderate the relation between exposure to inclusive materials and attitudes was examined but not supported. KEYWORDS: sexual minority; heterosexual attitudes; inclusive curriculum 
THE IMPACT OF AN INCLUSIVE CURRICULUM ON ATTITUDES TOWARD SEXUAL MINORITY POPULATIONS

\author{
KIRSTIN K. JOHNSON
}

A Dissertation Submitted in Partial

Fulfillment of the Requirements for the Degree of

DOCTOR OF PHILOSOPHY

Department of Psychology

ILLINOIS STATE UNIVERSITY 
(C) 2021 Kirstin K. Johnson 
THE IMPACT OF AN INCLUSIVE CURRICULUM ON ATTITUDES TOWARD SEXUAL MINORITY POPULATIONS

\author{
KIRSTIN K. JOHNSON
}

COMMITTEE MEMBERS:

Brea M. Banks, Chair

Matthew Hesson-McInnis

Eric Wesselmann

Jason Whitesel 


\section{ACKNOWLEDGMENTS}

To all individuals who helped me accomplish all I set out to over the past 5 years, thank you. I could not have done this without the support of countless family members, friends, and colleagues. Though I've received support from too many to name, there are a certain set of individuals I'd like to address more personally.

To my parents, thank you for fostering my strong-willed nature in a way that allowed me to grow up believing I could do anything I set out to do. Had that fire been put out at an early age like it is for many little girls, I would not have been able to accomplish this feat. Thank you for the unconditional love and support from day 1 and for going out of your way to remind me of the importance of a work-life balance.

To my siblings, thank you for always being a phone call away. Thank you for being a distraction, even when I did not think I had time for it. Thanks for reminding me that you were looking up to me on days I felt like throwing in the towel. What I accomplished with your help is nothing more than what you can do. You are all capable of anything you put your minds to, please never forget that.

To my cohort, thank you for the laughs, friendship, and solidarity over the last 5 years. Not only will I leave graduate school with a group of esteemed colleagues that have so much to offer the field but also with memories that will last a lifetime, and because of that I feel more thankful than I can express. I look forward to seeing each of you grow as you embark on your professional and personal journeys, and I cannot wait to see the countless new memories we will form. We're all on the rocket ship, my friends. 
To my dissertation chair, Dr. Brea Banks, thank you for your continued support during my graduate training. Thank you for making my dream research idea become a reality. Without your continued patience, compassion, push, and mentorship I would not be leaving my graduate training as the professional I am today. To Dr. Eric Wesselmann, thank you for agreeing to be part of my dissertation committee. You played a great role in me getting to where I am today and that is all thanks to your continued support since my first semester at ISU. How fitting it is that the professor who taught my first ever course at ISU will be part of my last ever training requirement at ISU. To Dr. Matthew Hesson-McInnes and Dr. Jason Whitesel I appreciate you each bringing your own expertise to the table and being enthusiastic about my research topic. It was a pleasure to work with each of you as members of my dissertation committee.

Lastly, to my son, Maximo Dale, I owe you more thanks than I can ever put into words. You are the reason I do what I do every single day. On days I felt like I was in over my head your presence reminded me to keep going. There was no motivation like knowing those big brown eyes were watching my every move. I strive to make you proud and to show you that the world is ours for the taking.

K.K.J. 


\section{CONTENTS}

Page

ACKNOWLEDGMENTS

CHAPTER I: OVERVIEW OF STUDY 1

CHAPTER II: REVIEW OF THE LITERATURE 4

$\begin{array}{ll}\text { Sexual Minority Populations } & 4\end{array}$

$\begin{array}{ll}\text { Attitudes } & 5\end{array}$

$\begin{array}{ll}\text { The Relationship Between Attitudes and Behaviors } & 7\end{array}$

$\begin{array}{ll}\text { Attitudes Toward Sexual Minority Individuals } & 10\end{array}$

$\begin{array}{ll}\text { Victimization } & 15\end{array}$

$\begin{array}{ll}\text { Mere Exposure } & 21\end{array}$

$\begin{array}{ll}\text { Curriculum } & 26\end{array}$

$\begin{array}{ll}\text { Present Study } & 31\end{array}$

CHAPTER III: METHODS

$\begin{array}{ll}\text { Participants } & 34\end{array}$

$\begin{array}{ll}\text { Measures } & 34\end{array}$

Procedure and Design $\quad 36$

$\begin{array}{ll}\text { CHAPTER IV: RESULTS } & 38\end{array}$

$\begin{array}{ll}\text { Preliminary Analyses } & 38\end{array}$

$\begin{array}{ll}\text { Primary Analyses } & 39\end{array}$

CHAPTER V: DISCUSSION 41

Limitations and Future Research $\quad 42$

REFERENCES 46 
APPENDIX C: LESBIAN, GAY, AND BISEXUAL KNOWLEDGE AND ATTITUTDES

SCALE FOR HETEROSEXUALS 


\section{CHAPTER I: OVERVIEW OF STUDY}

Attitudes toward sexual minority individuals, or those who identify as any sexual orientation that is not heterosexual, have become more positive over time, likely due to policy change such the decriminalization of homosexuality, the legalization of non-heterosexual marriage, and employment protections in the United States (McCarthy, 2019). However, a large percentage of Americans still hold negative attitudes toward sexual minority individuals (Gay and Lesbian Alliance Against Defamation, 2019). Educational institutions symbolically annihilate sexual minority individuals through the selection and implementation of heteronormative curricula materials. Heteronormativity is the belief that heterosexuality (i.e., sexual attraction solely to the "opposite" sex) is the default sexual orientation of all individuals (Harris \& White, 2013). Heteronormativity is present within the "hidden curriculum," which accounts for the norms, attitudes, and beliefs held by an educational institution (Alsubaie, 2015). For example, listing "mother and father" on forms, selection of a homecoming "king and queen," and school policies that forbid the use of materials with sexual minority individuals represented all align with heteronormative beliefs in schools, as they ignore variation in sexual identity or orientation. The "hidden curriculum" functions as a form of social control as practices and lessons like these impose sexual orientation subordination and hetero-superiority (DePalma \& Atkinson, 2010; Walton, 2005; MacGillivary, 2000).

It is important to understand how schools may bring about negative attitudes toward sexual minority individuals, as researchers have asserted negative attitudes toward minority groups are predictive of discriminatory behaviors (i.e., aggressive acts based on one's identity; Rey \& Gibson, 1997). Because it is known that negative attitudes toward sexual minority individuals exist, it is consistent that aggressive acts, both intentional and unintentional, are 
widespread across settings, including in schools (Galupo \& Resnick, 2019; Dashow, 2018). Aggressive acts toward sexual minority individuals negatively impact victims, as sexual minority individuals who experience aggressive acts against them are more likely to have depressive symptoms, an elevated risk of self-harm, and higher levels of suicidal ideation (Almeida et al., 2009Kosciw et al., 2018; Herek, 2009). Additionally, they are more likely to miss school, have a lower grade point average, and be disciplined at school (Kosciw et al., 2018). Given what is known about the impacts of victimization, it is crucial to understand how to diminish such acts toward sexual minority individuals. One way to reduce discriminatory behaviors is to bring about more positive attitudes towards marginalized groups.

In 2018, there were an estimated 56.6 million children enrolled in primary and secondary schools and 19.9 million students enrolled in colleges and universities across the United States (National Center for Education Statistics, 2018). These data indicate that approximately $25 \%$ of the United States population is enrolled in a primary, secondary, or post-secondary institution annually. Because so many individuals are exposed to materials presented in educational settings, it is likely that such institutions may be the ideal setting to bring about such positive change by interrupting heteronormative practices. The implementation of an inclusive curriculum may accomplish this goal (Goodhand \& Brown, 2016). An inclusive curriculum offers diverse representation of individuals. Relevant to this study, an inclusive curriculum would include individuals who identify as sexual minority individuals. The National Association of School Psychologists (NASP) suggested that an inclusive curriculum in schools would include discussing sexual orientation development theory, reading books written by sexual minority individuals, becoming aware of relevant history, and discussing sexual minority individuals' relationships in health classes, among many other proposed ideas. It is possible that an inclusive 
curriculum would lead to more positive attitudes toward sexual minorities as researchers have concluded that individuals' attitudes become more favorable toward minority groups when they are positively exposed to such groups (Zebrowitz et al., 2008). The purpose of the current study was to examine the impact of inclusive academic materials on heterosexual individuals' attitudes toward sexual minority populations. 


\section{CHAPTER II: REVIEW OF THE LITERATURE}

\section{Sexual Minority Populations}

The term sexual orientation refers to not only an individual's an ongoing pattern of sexual behavior but also their pattern of emotional and romantic relationships with other individuals (American Psychological Association, 2015; van Anders, 2015; American Psychological Association, 2008. Though sexual orientation has historically been described through the use of discrete labels (e.g., homosexual, bisexual, homosexual), researchers have indicated that this approach is likely not comprehensive. That is, researchers have found that some individuals fall within a "gray-area" and therefore none of these categories may appropriately describe their sexual orientation (Salomaa \& Matsick, 2019). As a result, the terms available to describe nonheterosexual individuals' identities have expanded in recent years. Because of this, I will use the term sexual minority to refer to any sexual orientation which does not align with heterosexuality in order to be inclusive to all individuals and their personal identities.

In the United States, there are an estimated 10.3 million adults who identify as sexual minority individuals, which accounts for approximately $4.5 \%$ of the adult population in the country (LGBT Data Interactive, 2019). It is estimated that the percentage of individuals identifying as a sexual minority under the age of eighteen is even greater. Specifically, in a study of nearly 15,000 students enrolled in 144 high schools across the United States, approximately $10.4 \%$ of individuals identified as a sexual minority (i.e., gay, lesbian, bisexual) and another $4.2 \%$ reported that they were not sure of their sexual orientation at the time of completing the survey (Kann et al., 2017). Further, there is a positive trend of individuals identifying as sexual minority individuals in the United States, as more people have identified as a sexual minority than in the previous year consecutively for six years. Moreover, younger populations are 
identifying as sexual minority individuals at higher rates than those from older birth cohorts. For example, $8.2 \%$ of Americans born between 1980 and 1999 (i.e., members of the millennial generation) identify as a sexual minority, as compared to 3.5\% of Americans born between 1965 and 1979 (i.e., members of generation X; Newport, 2018). It is likely that self-awareness of one's sexuality, along with willingness to self-identify as a sexual minority individual explain this trend. Regardless, is seems that the presence of sexual minority individuals within educational settings will continue to become more prominent, making the present study important and relevant.

\section{Attitudes}

Nearly a century of research in social psychology and related fields exists regarding attitudes, relatively enduring evaluations of social groups (Crano \& Prislin, 2008). Underlying nearly each definition of attitudes is that they are evaluative in nature (Albarracin et al., 2005). That is, researchers have agreed through the formation of similar definitions that attitudes provide an individual's evaluation, or tendency to express more positive or negative feelings and beliefs, of a specific concept. Individuals hold attitudes about all concepts in their environment, which may include, but is not limited to, holding attitudes toward other people, social groups, ideas, or products. For purposes of this study, the term attitude will refer to a set of beliefs and feelings related to a specific concept (Hogg \& Vaughan, 2005). Attitudes are typically categorized as either implicit or explicit (Carruthers, 2018). Explicit attitudes are deliberate and conscious, meaning individuals are aware of and able to report on these feelings and beliefs (Crano \& Prislin, 2008). Implicit attitudes are evaluations of a concept that are not available to an individual's conscious (Carruthers, 2018). 
Attitudes are acquired in a variety of ways. Some researchers assert that attitudes are partially inherited from an individual's parents. Specifically, researchers in one study examined the similarities and differences in attitudes in various sets of monozygotic and dizygotic twins (Olson et al., 2001). Researchers in this study found that attitudes of twins were similar for a majority of constructs studied. However, environmental factors accounted for a majority of variance in attitude factors. For example, shared experiences of twins accounted for the relation between athletic ability and attitudes toward athleticism to a greater degree than genetics. Thus, identifying the importance an individual's environment also plays in formation of attitudes.

Several researchers have specifically studied how a person's environment impacts their development of attitudes. One important factor impacting attitude formation is the people who make up an individual's environment, such as peers, parents, and siblings. Through processes like modeling and social learning, individuals may form attitudes similar to those held by the people in their environment (Zimbardo, 1991). In one study, participants responded to surveys that measured attitudes toward sexual minority individuals and identified up to eight peers at the same school they considered friends. From these nominations, researchers divided students who reported having more contact with one another than with others into groups, resulting in 18 total groups. Researchers used the self-reports of individual's attitudes toward sexual minority individuals and compared them to those composing their peer group. Further, researchers asked participants to repeat the same measure of attitudes toward sexual minority individuals eight months later and again compared these attitudes to those in their peer group. Researchers asserted that negative attitudes were more coherent within peer groups when measured the second time. The association between individuals self-reported attitudes toward sexual minority individuals and peer group attitudes were stronger the second time they were measured, thus, 
suggesting peer groups have an influence on attitude development, likely through modeling and social learning (Poteat, 2007).

Along with the individuals in one's environment, attitudes may be influenced by direct and indirect experiences. For instance, researchers have determined that mere exposure to specific stimuli make individuals view similar stimuli in a more favorable way (Zajonc, 1968). Specifically, effects of mere exposure have been found to lead to more positive attitudes toward racial minorities (Zebrowitz et al., 2008). In conclusion, it is likely that attitudes are formed as a result of a variety of genetic and environmental factors. For the purpose of the present study, I am most interested in attitudinal change, because we know that an individual's attitude impacts the behaviors one displays.

\section{The Relationship Between Attitudes and Behaviors}

Whereas the extent to which attitudes predict behaviors has been widely debated (Kraus, 1995), research suggests that there exists a relation between attitudes and behavior, as attitudes towards various constructs have been found to predict behaviors. In one study, a set of researchers surveyed over 250 women regarding their thoughts and beliefs toward using birth control pills, birth control pills in general, and other forms of birth control (i.e., attitudes) as well as their self-reported use of such contraceptives (i.e., behavior). Researchers concluded that individuals who reported they were more open to the using birth control pills were more likely to use them (Jaccard et al., 1977). In addition, the same researchers conducted an additional study in which participants provided insight into their attitudes surrounding religion, church, and attending church. They were also asked to report if they attended church the following Sunday, Researchers found that all attitudes were predictive of the actual behavior of attending church as participants who reported more favorable attitudes toward religion, church, and attending church 
were more likely to have attended church than those holding more negative attitudes. In both these studies, researchers concluded that the best predictor of behavior was an attitude that directly linked to behavior. Specifically, in the study about contraception, researchers found that there was a greater relation between the scale measuring attitudes toward taking birth control pills and the behavior of taking such pills than there was between the behavior and the attitudes toward birth control pills in general and other forms of birth control. In the study about church attendance, researchers found that the most closely related attitude to the behavior (i.e., attending church) was attitude toward attending church, rather than attitudes toward church and attitude toward religion (Jaccard et al., 1977).

Although the research described above appears to reflect the importance of attitudinal scales reflecting a target behavior, other researchers have concluded more general attitudes are still predictive of behavior. Researchers in one study examined the relation between racial attitudes and discriminatory behaviors in the hiring process (Stewart \& Perlow, 2001). In this study, 181 participants first completed a measure of racial attitudes. After completing this measure, participants took part in the evaluation and hiring process portion of the study. Specifically, participants were given a job description of either a high (e.g., architect) or low (e.g., janitor) status job and a job resume for either a Black or white applicant. Participants were asked whether they would hire the individual and how confident they were in their decision. Researchers concluded that although there were no differences in the percentage of individuals hired based on race, that individuals with greater negative attitudes toward Black individuals were more confident in assigning a Black individual to a low status job than high status jobs. These data suggest discriminatory behaviors related to attitudes are present but may operate in subtle ways (Steward \& Perlow, 2001). 
In a more recent study of the relation between attitudes and discriminatory behaviors, Carlsson and Eriksson (2017) utilized survey data on individuals' attitudes toward ethnic minoritized populations and direct measures of discriminatory behavior toward individuals who hold such identities. Specifically, researchers in this study sent inquiries to landlords who were advertising vacant apartments in which they used names that were either stereotypical Arabic/Muslim names or stereotypical Swedish names. The researchers sent a total of 5,825 inquires, 2,878 including a typical Arabic/Muslim name. When landlords responded, researchers grouped them in to three categories: positive (i.e., landlord explicitly stated it is possible to view an apartment), negative (i.e., when the landlord explicitly state it is not possible to view an apartment), and no response. Across response types, there was a significant difference between ethnic groups. That is, when a stereotypical Arabic/Muslim name was used participants were more likely to receive a negative response. Researchers classified landlords' attitudes to match the attitude held by the majority of individuals in the specific region of the country they were by using previously gathered data on ethnic attitudes. Landlords who resided where there are greater levels of negative attitudes were more likely to send a negative response, thus, providing evidence that there is a relationship between attitudes and discriminatory behaviors (Carlsson \& Eriksson, 2017).

Relevant to the current study, researchers have found that heterosexual individual's attitudes toward sexual minority individuals relate to the behaviors in which they engage. Specifically, Rey and Gibson (1997) recruited over 200 college students to participate in their study on homophobic behaviors and discriminatory behaviors. Participants provided self-reports of their homophobic attitudes along with self-reports about discriminatory behaviors toward sexual minority individuals. Researchers found that individuals who were more homophobic 
(i.e., had homophobic attitudes) reported displaying a greater number of discriminatory behaviors toward sexual minority individuals.

Researchers also examined the link between negative attitudes toward homosexual individuals and discriminatory behaviors in a more recent study. Social psychologists, Melanie and Todd Morrison (2011) recruited nearly 200 participants who were asked to read profiles for hypothetical candidates running for a political office. Some profiles indicated involvement in a sexual minority organization, while others did not. Upon examining the profile, participants were asked to complete a scale to assess behavioral intentions (e.g., likelihood they would help the candidate by making posters, become friends with candidate, etc.) All participants then completed a variety of scales meant to assess negative attitudes toward gay men and lesbian women. Researchers concluded that individuals who had higher levels of negative attitudes toward sexual minority individuals were less likely to have behavioral intentions toward helping the gay candidate (Morrison \& Morrison, 2011). The studies described above provide evidence that an attitude-behavior relationship exists and is directly relevant to the current study.

\section{Attitudes Toward Sexual Minority Individuals}

Specific to the current study, it has been shown through prior research that differences in attitudes toward sexual minority individuals. For example, in one study undergraduate students were asked to rate their attitudes toward sexual minority individuals and to provide a rationale as to why they held these beliefs (Hans et al., 2012). Researchers discussed five sources identified as explanations for attitudes toward sexual minority individuals. Interactions with sexual minority individuals was one source, which accounted for individuals' personal relationships and interactions with friends, family members, and acquaintances who identified as sexual minorities. Personal interaction with sexual minority individuals was associated with favorable 
attitudes, as $70 \%$ of participants who cited personal experiences with gay men or lesbians held favorable attitudes. Nearly half of the participants cited social justice beliefs (e.g., importance of equal treatment) as a source of their favorable beliefs toward sexual minority individuals. However, this egalitarian attitude accounted mainly for indifferent or "tolerant" attitudes toward sexual minority individuals rather than full acceptance with a majority of individuals stating that sexual minority individuals should be treated fairly even though they disagree with their "lifestyle." Participants also cited parental beliefs as source of their attitudes. Nearly $80 \%$ of participants who held unfavorable attitudes toward sexual minority individuals cited religious beliefs. Lastly, participants referenced their beliefs about the origin of sexual orientation (e.g., a biological basis of sexual orientation) as impacting their beliefs about sexual minority individuals, though some individuals offered this to explain their negative attitudes while others cited it to attest to favorable attitudes (Hans et al., 2012).

Researchers have also identified several socio-demographic factors that predict attitudes toward sexual minority individuals. Gender is one such variable, as researchers have asserted that men typically hold more negative attitudes toward sexual minority individuals than women (Harbaugh \& Lindsey, 2015; Kite \& Whitley, 1996). Researchers have also identified racial differences in attitudes toward sexual minority individuals, though these results are highly inconsistent, as some researchers have identified more negative attitudes held by people of color (Glick et al., 2015), although others found no differences (Herek \& Capitanio, 1995). These discrepancies are likely better explained by other factors such as education and socioeconomic status that may interact with race (Holland et al., 2013). Additionally, individuals who report a greater conservative political affiliation have been found to have more negative attitudes toward sexual minority individuals (Woodford et al., 2012). Students enrolled in colleges and 
universities who are actively involved in a sorority or fraternity have been found to have more negative attitudes toward this group (Worthen, 2014). More specifically, men who actively participate in fraternities are more likely than woman who are in sororities to hold negative attitudes toward both men and women who identify sexual minority individuals. Women, however, are more likely to have negative attitudes of women who identify as a sexual minority as opposed to men who hold the same identity (Worthen, 2014).

Scholars have also found that individuals who hold higher levels of religiosity (i.e., commitment to religion or a religious group) also tend to have more negative attitudes toward sexual minority individuals (Harbaugh \& Lindsey, 2015; Finlay \& Walther, 2003). Specifically, researchers in one study recruited nearly 200 undergraduate students to provide reports of religiosity and attitudes toward sexual minority individuals. Researchers found that individuals who had a greater level of commitment to their religion (i.e., higher level of religiosity) had more negative attitudes toward sexual minority individuals (Harbaugh \& Lindsey, 2015). In a similar study, researchers sampled over 1,000 participants and gathered information about their attendance at religious services and their attitudes (i.e., a dimension of religiosity) toward sexual minority individuals. Researchers found the more a person attended religious services, the more negative their attitudes were toward sexual minority individuals (Finlay \& Walther, 2003). Thus, providing further support for the relation between religiosity and attitudes toward sexual minority individuals. Still, to be fair, one recent outlier dissertation study found that higher levels of religiosity predict more positive attitudes toward sexual minority individuals with religious women at a faith-based university with Quakerism roots holding more positive attitudes while their male counterparts held more negative attitudes (Cormier Castaneda, 2019). 
Data suggests that there have been changes in attitudes towards sexual minority individuals. In 1977, a sample of Americans was recruited and asked to respond to a variety of questions relating to sexual minority individuals and their rights. In 2019, researchers recruited another sample of participants, including individuals from all 50 of the United States and the District of Columbia, and asked them to respond to the same set of questions. Given the collected data, views Americans hold about sexual minority populations today are vastly different than those held by individuals decades ago (McCarthy, 2019). Specifically, in 2019, respondents were more likely to express the beliefs that gay people should have equal rights in terms of job opportunities ( $93 \%$ compared to $56 \%$ ), that same-sex relations between consenting adults should be legal ( $83 \%$ compared to $43 \%$ ), and that same-sex couples should be able to adopt children ( $75 \%$ compared to $14 \%$ ). Thus, findings from the two-wave Gallup poll represent a positive trend in attitudes toward sexual minority individuals and their rights.

Researchers hypothesize that policy changes account for a portion of the greater levels of acceptance, tolerance, and visibility for sexual minority individuals (Kite \& Bryant-Lees, 2016). An example of a landmark policy change that appears to have had a positive impact on the societal views of sexual minority individuals and their rights is the Supreme Court of the United States' ruling that same-sex marriage is a guaranteed right nationally (Obergefell v. Hodges, 2015). In 2014, prior to the aforementioned Supreme Court ruling, an estimated 55\% of adults in the United States believed that marriages between same-sex couples should be recognized by the law as valid and granted the same rights as heterosexual marriages. By 2016, only one year after the formal removal of bans on same-sex marriage across the United States, an estimated $61 \%$ of American adults believed the same (Gallup, 2019). The data offer one piece of evidence 
suggesting that policy changes have led to societal shifts in the general population's attitudes towards sexual minority individuals and their rights.

While attitudes toward sexual minority individuals appear to have improved, it is evident that many American citizens still hold negative attitudes toward sexual minority individuals. The Gay and Lesbian Alliance Against Defamation (GLAAD) collected data from 1,754 adults in the United States who did not identify as sexual minority individuals to examine American's attitudes and beliefs towards sexual minority individuals (2019). GLAAD reported finding that Americans believe sexual minority individuals should have the same rights as their heterosexual counterparts, as $80 \%$ of participants reported this as a belief. However, GLAAD also reported an increasing percentage of individuals who expressed being at least somewhat uncomfortable being put in a variety of situations with an individual who identified as a sexual minority. Specifically, GLAAD compared participants responses in 2019 to those collected the year before and found a decrease in overall comfort with the following situations: learning their child has a lesson on LGBT history in school, learning their child is placed in a class with an LGBT teacher, and learning a family member is LGBT. GLAAD also reported a decline in heterosexual individuals who are allies, defined as heterosexual respondents who are at least somewhat comfortable in all situations involving sexual minority individuals. Specifically, researchers determined that participants between the ages of 18 and 34 showed the biggest decrease in being an ally from 2018 to 2019 , as only $45 \%$ of this population reported being an ally compared to $53 \%$ in the previous year (GLAAD 2019).

Based on these data, it is evident that, regardless of societal shifts in attitudes toward sexual minority individuals, there is still a significant difference between heterosexual attitudes toward sexual minority individuals and those held toward their heterosexual counterparts. That 
is, there are still many people in the United States who display sexual prejudice, or negative attitudes toward sexual minority individuals. As mentioned above, previous researchers have identified socio-demographic characteristics that may be predictive of these negative attitudes. Given what is known about the relation between attitudes and behaviors, it is important to understand these attitudes toward sexual minority individuals and who may be most likely to hold such attitudes. Specifically, it is clear that sexual prejudice is related to the victimization sexual minority individuals experience at alarmingly high rates (Herek, 2000). Going forward, I will focus on the belief that sexual prejudice is directly linked to the high levels of aggression against sexual minority individuals. Further evaluation of such victimization and discriminatory behaviors toward sexual minority individuals, along with the negative implications of such behaviors, will be further explored below, and in the pages to follow.

\section{Victimization}

Inetrpersonal discrimination is the act of treating an individual unjustly based solely on their membership in a particular group (Badgett \& Frank, 2007). Individuals may be discriminated against for a variety of identities or personal characteristics (e.g., gender, race, sexual orientation, ability, etc.). Victimization is the act of one individual targeting another individual with aggressive behaviors (Hawker \& Boulton, 2000). When victimization occurs as a result of the victim's membership in a particular group, it is a form of discrimination. Victimizatiotn may also occur at the institutional level which is evident when discrimination is embedded in procedures and policies.

Researchers suggest that aggression may be intentional or unintentional (Davis, 2004). Specifically, intentional aggression occurs when an individual displays a behavior with the purpose of causing harm to another. Intentional aggression may involve physical aggression such 
as hitting, kicking, punching, or shoving, and verbally aggressive behavior such as name calling and teasing. On the other hand, unintentional aggression is the process of displaying a behavior which causes harm to a victim without the purpose of doing so (Davis, 2004). Microaggressions, which are verbal remarks or subtle behaviors that communicate hostile, derogatory, or negative slights or insults toward a minoritized group largely falls under this category (Nadal, 2008). Microaggressions can be insulting (e.g., saying "that's so gay" to refer to something unfavorable) or invalidating (e.g., telling a person who discloses their sexual orientation that they do not look gay), both of which demonstrate to the receiver that they are different and do not belong. Harm caused by unintentional aggression may have lasting physiological, social-emotional, and cognitive effects on the victims of these behaviors (Banks \& Cicciarelli, 2019; Nadal et al., 2014).

In the United States, the victimization of sexual minority individuals occurs at alarmingly high rates (Berrill, 1990). Instances of aggression, both intentional and unintentional, occur in a variety of settings such as work, school, and in the community. Given the prevalence of these behaviors, researchers have sought to understand better the victimization experiences of sexual minority individuals. In one study, Pilkington and D'Augelli (1995) recruited over 200 participants in urban areas who identified as sexual minoritized individuals between the ages of 15 and 21 to provide information about their experiences with victimization. Specifically, participants provided frequency counts for the number of times they had experienced nine various forms of intentional aggression (e.g., verbal insults, being chased or followed, being punched, hit, kicked, or beaten). Additionally, participants were asked to report the context (i.e., home, school, among friends, work, community) in which the victimization occurred. Pilkington and D'Augelli (1995) concluded that approximately $83 \%$ of participants had experienced at least 
one form of intentional aggression, and $4 \%$ had experienced all nine forms of aggression. Further, these victimization experiences occurred across all contexts.

In another study, heterosexual participants were asked to self-report instances in which they were the perpetrator of harassment, violence, and isolation of sexual minority individuals (Rey \& Gibson, 1997). Approximately $95 \%$ of participants admitted to perpetrating at least one discriminatory act toward a sexual minority individual. Of these participants, $32 \%$ committed a discriminatory act which was considered moderately harmful or higher. Another $8 \%$ reported taking part in one of the most severe acts toward a sexual minority individual (i.e., use of sexually explicit comments, verbal harassment, violent threats, vandalization of property, physical aggression, or assault using a weapon). Participants reported these behaviors were intentional and were displayed for a variety of reasons such as boredom, not approving of homosexuality, anger, or because they felt that an individual made a sexual advance (Rey \& Gibson, 1997).

Under certain circumstances, victimization may be so extreme that it may involve criminal acts. When victimization occurs as a result of bias toward an individual's group membership and it is criminal, it is considered a hate crime. Herek (2009) sought to determine the prevalence of criminal victimization toward sexual minority individuals by gathering information from over 650 participants in the United States. Specifically, the researcher obtained reports of victimization toward participants that was perceived as a result of their sexual identity or orientation. Researchers found that approximately $25 \%$ of adults surveyed had either experienced a crime against them as a result of their sexual orientation or had experienced an attempted crime against them (Herek, 2009). In 2018, the Federal Bureau of Investigations (FBI) released an annual report on the number of hate crimes from the previous year. It was indicated 
that approximately 1,100 hate crimes occurred based on an individual's actual or perceived sexual orientation, which accounted for approximately $16 \%$ of total hate crimes in the United States. Although this number is high, it is likely that it only represents a fraction of such occurrences, as hate crimes are underreported, and individual law enforcement agencies are not required to report hate crimes to the FBI. Therefore, this number represents only the hate crimes that were not only initially reported to law enforcement but then reported to the FBI (Dashow, 2018).

Sexual minority individuals also experience unintentional victimization across various settings. Galupo and Resnick (2016) surveyed 100 working adults who identified as sexual minority individuals to gain a better understanding of unintentional victimization in the workplace. All participants included in the study provided examples of microaggressions they had observed in the workplace (e.g., a colleague telling a sexual minority individual starting a job at a public high school that they would be a great fit in a neighboring school which serves several LGBTQ students because of this employee's "gender issues"; Galupo and Resnick, 2016, p. 279). Additionally, most individuals felt as though such instances were offensive; negatively impacted their moods, wellbeing, and relationships; changed the expectations of them in their place of employment; and caused them to be less productive at work. For example, one participant described how they were expected to attend events which were meant to draw large crowds of sexual minority individuals upon disclosing their sexual orientation, thus adding to their workload (Galupo and Resnick, 2016).

Because many individuals in the United States spend a significant amount of time in schools and other educational settings, it is important to understand sexual minority individuals' specific experiences of victimization in these settings. Kosciw and colleagues (2018) gathered 
data from about 23,000 students between the ages of 13 and 21 from all 50 states and the District of Columbia to assess further these experiences. They found that participants who identified as a sexual minority experienced both unintentional and intentional forms of aggression at significantly higher rates than their heterosexual peers. Specifically, approximately $87 \%$ of sexual minority students who participated reported being harassed or assaulted based on their identity. Intentional aggression reported included verbal harassment (70\% reported), physical attacks (30\% reported), and sexual assault in schools (57\%; Kosciw et al., 2018). Unintentional aggression reported included hearing words like "gay" and "faggot" used to indicate something was not liked or was perceived as "uncool.” Additionally, policies which are discriminatory in nature were reported as unintentional forms of victimization. For example, policies requiring dates to school dances to be of the "opposite" sex or being disciplined for public displays of affection only when it is between sexual minority individuals and not heterosexual students. It is apparent that a significant number of individuals who hold sexual minority identities experience victimization within educational settings in the United States.

Victimization causes significant harm to receivers. Almeida and colleagues (2009) collected responses from over 1,000 high school students to further examine the impacts of victimization in schools specifically. They asked participants to provide the number of times they were discriminated against and to complete a measure of depressive symptomology. The researchers found that sexual minority individuals experienced higher levels of perceived discrimination. Among those who reported higher levels of perceived discrimination, the researchers found higher levels of depressive symptomology, an elevated risk of self-harm and suicidal ideation, and overall emotional distress. 
Kosciw and colleagues (2018) examined the impacts of victimization toward sexual minority individuals in educational settings. In the study of 23,000 students described previously, the researchers asked participants to report on specific outcomes that had resulted from discrimination within the school. They found a similar trend of several negative outcomes. Specifically, the researchers concluded that sexual minority individuals who had experienced victimization were more than three times as likely to have missed school in the past month than those who had not experienced victimization. Additionally, they concluded that individuals who were victimized as a result of their sexual orientation had a lower grade point average (GPA) and were more likely to have been disciplined at school than those who had not experienced such victimization. Researchers, like those in the study described above, found that individuals who had been victimized based on their sexual orientation were more likely to experience higher levels of depression and had lower self-esteem.

It is evident that victimization is prevalent across social contexts in the United States. This includes workplaces, schools, and in the communities. A high percentage of individuals are enrolled in educational settings each year in the United States; therefore, it is concerning that victimization is occurring at alarmingly high rates in such settings. Victimization occurs in a variety of forms, as it is sometimes unintentional but is frequently intentional. Victimization causes significant harm and can lead to a variety of negative outcomes. Because of this, it is crucial to understand how victimization of sexual minority individuals in educational settings may be diminished or eliminated. The purpose of the current study is to propose a means of diminishing victimization of individuals in educational settings. 


\section{Mere Exposure}

Exposure is the process by which a stimulus is accessible in a person's perception (Zojanc, 1968). When an individual is repeatedly exposed to a neutral, novel object, they begin to have more favorable attitudes toward such stimuli. This phenomenon is known as mere exposure or the familiarity effect. Research on mere exposure has been replicated with multiple stimuli, in different settings, and with different subject populations; and the effects have remained consistent (Grush, 1976). In one of the earliest known studies examining mere exposure, researchers examined the relation between word frequency and word rating. Participants first rated a series of words on how good or bad they were semantically. After rating the words, participants were exposed to the words from 1 to 10 times. When the word was exposed, participants were required to look at and pronounce the word. Upon completion of the word exposure task, participants were asked to rate the words using the same good-bad scale. Researchers found that participants who were exposed to words a greater number of times, rated the same words as more favorable than words they had not been exposed to (Johnson et al., 1960).

In another study researchers examined the exposure-favorability relationship using Chinese calligraphy (Zojanc, 1968). Participants were told that the purpose of the study was to learn a foreign language. Participants were instructed to pay close attention to the character and that each character represented an adjective. All participants were exposed to each character a specific number of times. After exposure, participants were asked to rate the character on the good-bad scale. Consistent with previous findings, participants were more likely to rate characters they had been exposed to more frequently with a higher level of goodness than those they were exposed to less frequently. Although participants in both studies were asked to rate 
words on how good or bad they perceived them to be based on their meanings and not explicitly asked to rate their likability or attitude toward a word, researchers hypothesized that no difference would be present if asked to directly rate their attitude (Zojanc, 1968).

To expand research and test this hypothesis, Zojanc (1968) recruited participants who were exposed to a stimulus and later asked to rate their direct attitude toward the object. Photographs of men were used as the stimulus in this study. Participants were shown each photograph a different number of times. After being exposed to all photos, participants were asked how much they may like each man on a 7-point Likert scale. Consistent with previous findings, participants had more positive attitudes toward photographs of men they had been exposed to a greater number of times. Results like those presented above have been used as the basis for the argument that mere exposure may be used to reduce prejudice, as repeated exposure to individuals who hold marginalized group identities may increase the beholder's favorable regard of said person. To reduce prejudice, generalizability would be necessary. That is, the change in attitude toward a specific object would need to be generalizable to similar stimuli.

In another study, researchers examined the affective generalization of stimuli using faces (Rhodes et al., 2001). Specifically, 330 participants took part in the two-phase study. In phase 1, participants were shown a series of black-and-white photographs and told to study each face in order to later make judgments about them. In phase 2, participants were exposed to the same images they had previously seen but also to a series of new unseen faces. Some of the unseen faces were composites of the previously unseen faces, whereas others were completely random. During the 15-seconds of exposure, participants were asked to rate the degree to which they liked each person depicted in the photograph on a 10-point Likert scale. Researchers found that when exposed to previously seen photographs, participants ranked faces they had seen more frequently 
as more likable. Further, when shown unseen faces, participants rated faces that were composites of previously shown faces as more likable than random unseen faces, thus, supporting affective generalizability. In other words, increased likability toward an object after repeated exposure may be generalized to similar stimuli.

More specific to the purpose of the current study, Zebrowitz and colleagues (2008) examined the exposure-favorability relationship in relation to racial prejudice. In this study, 81 participants were randomly assigned to be exposed to either white or Korean faces. In the first part of this study, participants were exposed to a variety of faces, based on the condition they were randomly assigned. In part 2, participants were asked to rate how likable and familiar each face was to them. Participants rated novel (i.e., faces they were not previously exposed to) faces from the racial category they were randomly assigned as more likable than other-race faces. That is, individuals who were exposed to Korean faces were more likely to rate other Korean faces they had not been exposed to as more likeable than White faces they had never seen. These findings provide further evidence of affective generalization and the potential to reduce prejudice based on exposure to minority groups.

A great deal of research on the effects of mere exposure has been conducted regarding race and the reduction of racial prejudice. However, Flores and colleagues (2018) examined the effects of mere exposure on attitudes toward transgender individuals. In a study including over 2,000 participants, individuals were assigned to one of four conditions. Specifically, participants received either a vignette with information about the term "transgender" and no image (i.e., treatment group 1), the same vignette with a gender-congruent facial image included (i.e., treatment group 2), the same vignette with an incongruent facial image (i.e., treatment group 3), or a vignette about Japanese economic growth (i.e., control group). The purpose of the 
congruent/incongruent images were designed to provide representation of transgender individuals. Upon exposure to the specific materials under each condition, participants were asked to rate their attitudes about transgender individuals. Researchers concluded that mere exposure to transgender individuals, through information and images, led to more positive attitudes toward these individuals.

Other researchers have examined the effects of exposure to stimuli through other sources, such as film and television. Specifically, Mazur and Emmers-Sommer (2002) examined the impact of films on viewers' attitudes about sexual orientation and nontraditional families. All participants were first asked to complete questionnaires used to assess attitudes toward gender roles, families, and sexual minority individuals. Then, participants were assigned to view one of two films. The first film, Object of My Affection (1998), was presented to individuals randomly assigned to the experimental condition and included themes relating to gay men and nontraditional families (i.e., a pregnant woman who wished to raise her baby with a gay best friend/roommate rather than the baby's father). The other film, Father of the Bride II (1995), was presented to those exposed to the control group, as it included themes relating to traditional families and heterosexuality (e.g., a young man and woman who are married and announce they are expecting). Upon completion of the films, participants were asked to complete the same measures as before the film. Participants who viewed Object of My Affection (i.e., the experimental film) held more favorable attitudes toward "homosexual" individuals and their families than individuals who viewed the other film.

Further, Calzo and Ward (2009) examined the effects of everyday media exposure on individuals' attitudes toward sexual minority individuals. This study is important given the purpose of the current study, because based on what is known about mere exposure, it would be 
expected that the more frequently an individual was exposed to a stimulus, the more favorable their attitudes would be. Over 1,700 college students were first asked to respond to a series of measures to assess their general media use. Specifically, the researchers sought to understand participant's use of television, magazines, and movies. Upon completion of these measures, participants completed a series of questions used to assess their attitudes toward homosexuality. The researchers explored a variety of media outlets and determined that prime-time television comedies and drama, music videos, and teen and popular culture magazines were all predictive of more positive attitudes toward homosexuality. These types of media have higher levels of visibility and therefore there is greater evidence of mainstreaming effects.

Through research, it has been concluded that exposure to minoritized groups through a variety of outlets (i.e., images, television, magazines) leads to improved attitudes toward those groups. Although this is important and can have implications on prejudice reduction, it is also important to understand the effects repeated exposure to dominant groups can have on attitudes toward minority group individuals. Smith and colleagues (2008) explored this relationship by examining the effects of repeatedly exposing white participants to images of other white individuals and assessing their attitudes toward Black individuals. Specifically, in this study, participants were randomly assigned to either be exposed to white faces (i.e., experimental group) or to not be exposed to anything (i.e., control group). Upon the completion of the exposure process, participants were presented with the same photos they had been exposed to previously, along with novel photos, and asked to rate how much they liked the individual. Some of the novel photographs included photographs of Black individuals. Researchers found that participants who had been exposed to white faces had more negative attitudes toward Black individuals but did not have more positive attitudes toward white individuals. This finding 
suggests that when individuals from a dominant group are repeatedly exposed to individuals from the same group, attitudes toward individuals holding minoritized identities may become more negative. This further provides evidence to the impact familiarity plays when considering the impact of exposure.

Based on research conducted surrounding mere exposure, it is known that individuals who are exposed to repeated stimuli hold more favorable attitudes toward said stimuli. This in part is due to the familiarity of the stimuli. Because of this, exposure to individuals from a stigmatized group can be a means of reducing prejudice against such groups. Additionally, when individuals holding dominant identities are repeatedly exposed to individuals of their same group, their attitudes toward minoritized group individuals appear to become more negative, likely because the minority group is less familiar. Based on this knowledge, it is likely that exposure to sexual minority individuals in curriculum materials in schools would be beneficial in reducing prejudice in two ways. First, by exposing heterosexual individuals to sexual minority individuals repeatedly in curriculum materials, it is likely that their overall attitudes toward such individuals will become more positive as they would become more familiar. Currently, there are few curriculum materials that are inclusive of sexual minority individuals. Because of this scarcity of exposure, it is likely that repeated exposure to heterosexual individuals may lead to more negative attitudes toward sexual minority individuals. Therefore, this lack of exposure indicates a second way in which prejudice toward sexual minority individuals may be reduced by implementing inclusive curriculum materials.

\section{Curriculum}

Traditionally, curriculum has been defined as what is formally taught in schools and encompasses the content that was planned and purposefully presented through lessons, courses, 
and educational programs and materials (Egan, 2003; Toombs \& Tierney, 1993). However, more modern definitions of curriculum are more comprehensive, as they also include informal lessons disseminated to students in educational settings and those implicitly learned during extracurricular activates, social interactions, and so forth. (Wiles, 2008). The nonexplicit, informal lessons disseminated to students in educational institutions are frequently referred to as the hidden curriculum (Giroux et al., 1979; Martin, 1976). Norms, beliefs, and attitudes are disseminated in educational settings through hidden curriculum, which results from the unofficial ways which the formal curriculum is planned and organized, the side effects of hegemonic materials provided as a means of teaching the formal curriculum, and the overall procedures, policies, and functioning of the school, including staff and administrators who socialize students beyond the "official" lessons (Kelly, 2009). For the purpose of this study, curriculum is defined as a student's total experiences within the school setting and therefore will encompass both the formal and informal curriculum.

In the United States, school administrators at the primary and secondary level are typically responsible for selecting curricula that are to be implemented in specific classrooms, schools, and districts (United States Department of Education, 2008). While this is the case, federal mandates and standards guide selection and implementation of curricula. Individual states may have additional mandates and standards in place that further impact the selection and implementation of curricula. Responsibility for developing curricula for public post-secondary institutions, such as colleges and universities, is given to each individual institution and course instructors. Nonetheless, similar to primary and secondary institutions, post-secondary institutions must comply with certain federal and state mandates. Aside from assuring curricula meet federal and state standards, there is ample freedom given to the individuals responsible for 
selecting curriculum. Because of this freedom, the materials selected typically align with the attitudes, beliefs, and social norms of those who are selecting them (Kelly, 2009). Specifically, this is a result of the limited requirements given to an individual when tasked with selecting curriculum materials. Because of the minimal guidance and requirements, the individual has the freedom to select materials that are inclusive of knowledge they feel is relevant. The materials will also reflect the attitudes and values that are held by the individual, which are often consistent with those held by the greater society and may be reflective of social and political trends and beliefs (Mabwe, 2015). That is, the individual is influenced by societal views, attitudes, and beliefs, all of which are likely to make it into the curriculum. It is through the process of including certain individuals in lessons and ignoring or omitting others that the hidden curriculum is present and disseminates a set of beliefs, values, or norms to students.

The belief that heterosexuality (i.e., attraction solely to the "opposite" sex) is the default sexual orientation held by all is referred to as heteronormativity (Harris \& White, 2013). Heteronormativity is an example of a belief that may be disseminated to students through the hidden curriculum and has historically been present in schools. The practices and functioning of school staff and administrators impact the presence of heteronormativity in schools (Goodhand \& Brown, 2016). That is, such beliefs held by these individuals are typically represented through the implementation of specific policies and procedures, the selection of materials to be presented during lessons, and their own behaviors within the school. Examples of how the heteronormativity is present within the hidden curriculum in school settings includes listing "mother and father" on school forms, selection of a homecoming "king and queen," displaying materials in classroom or other common spaces that only depict heterosexual individuals, and school policies that prohibit the use of curriculum materials with sexual minority characters 
(DePalma \& Atkinson, 2010; MacGillivary, 2010; Walton, 2005). When materials are presented in schools that only represent dominant groups of individuals (e.g., heterosexual) and omit those who hold marginalized identities (e.g., sexual minority) it furthers the assumptions of dominance and heterosexual privilege.

The presence of heteronormativity in the hidden curriculum of a school may be detrimental to students who identify as sexual minority individuals. In a study by Castro and Sujak (2014), researchers interviewed students who identified as sexual minority youth with the purpose of better understanding the heteronormativity within the hidden curriculum in a high school setting. The researchers indicated that heteronormativity was prevalent in the hidden curriculum in the school. They reported findings that sexual minority youth consistently felt as though they were not included within the school environment. Committed to inclusive excellence in education, McDaniels (2017) suggests increasing support for sexual minority students by implementing an inclusive curriculum, or curriculum that is representative of diverse individuals and values culture, background, and experiences of all individuals exposed to the curriculum. By implementing an inclusive curriculum, researchers suggest, students may feel included in the educational environment which may lead to less stress.

In another study, Chesir-Teran and Hughes (2009) sought to examine the relation between perceived heterosexism in high schools and victimization rates among sexual minority students. Just over 2,000 participants who identified as sexual minority individuals were included in the study in which the researchers collected data relating to perceived availability of inclusive programs in the participants' schools and victimization. They found that the higher the perceived availability of inclusive programs, the lower the levels of perceived tolerance of harassment. Additionally, the researchers concluded that perceived levels of victimization were higher when 
there was a lower perception of inclusive programs. This research suggests that inclusive programs may interrupt heteronormativity in schools, and therefore may be beneficial to the well-being of sexual minority students. Similarly, researchers conducted a school climate study, which was administered to over 20,000 students between the ages of 13 and 21 . The researchers reported that sexual minority students who attended schools with inclusive curriculum materials were victimized less frequently, heard fewer derogatory remarks towards sexual minority individuals, felt safer at school, and had higher levels of academic achievement (Kosciw et al., 2018). The term "inclusive curriculum" was not defined in this study, and therefore, what was meant by this principle of inclusivity may differ between participants. However, it appears that the perception of having an inclusive curriculum had positive impacts on sexual minority students.

In recent years, policy change has led to the mandated inclusion of sexual minority representation in curriculum in some states. Specifically, California, New Jersey, Colorado, and Illinois have passed legislation that makes it mandatory to include individuals who identify as lesbian, gay, bisexual, and transgender in history lessons (Schwartz, 2019). While this is the case, several other states (i.e., Texas, Oklahoma, Louisiana, Mississippi, Alabama, and South Carolina) have laws in place which prohibit the inclusion of sexual minority representation in public school curriculum (Gay, Lesbian, and Straight Education Network, 2019). Whereas previous studies, like those described above, provide insight on the positive impact an inclusive curriculum has on students who identify as a sexual minority, they do not indicate whether such a curriculum impacts those who identify as heterosexual. With these recent policy changes, it is important to understand the broad effects of such materials. In the current study, I sought to examine the potential impacts a curriculum that is inclusive of sexual minority individuals has on 
heterosexual individuals' attitudes. It is believed that exposure to an inclusive curriculum will lead to more positive attitudes toward sexual minority individuals by heterosexual individuals and more broadly to more positive attitudes about social justice.

\section{Present Study}

There is a relation between an individual's attitudes and their behavior (Kraus, 1995). Negative attitudes toward a particular individual or group may lead to aggressive behaviors toward such people (Herek, 2000). For example, homophobic dismissal of "gay cancer" in the early 1980 s gave rise to heterosexual panic in the mid-1980s. In turn, aggressive acts (i.e., hate crimes) towards individuals who held sexual minority identities became one of the most common forms of victimization in the United States during this early period of AIDS awareness in the U.S. (Berrill, 1990). Individuals who identify as a sexual minority experience significantly higher levels of victimization across settings than their heterosexual counterparts (Waldo et al., 1998; Pilkington \& D’Augelli, 1995). Individuals who identify as a sexual minority experience drastically different levels of victimization in educational settings. Further, these behaviors toward sexual minority individuals in educational settings are predictive of several negative outcomes including higher levels of depressive symptoms, lower GPA, and a greater number of missed school days (Kosciw et al., 2018).

Because victimization of sexual minority individuals occurs at such high rates and has such negative outcomes, it is important to understand how to diminish the presence of such behaviors. To diminish behaviors, it is first necessary to improve the negative attitudes held toward sexual minority individuals. One way to improve attitudes toward a specific construct may be to increase exposure to it (Zojanc, 1968). In this case, to improve attitudes toward sexual minority individuals, heterosexual individuals should be exposed to sexual minority individuals 
more frequently. An inclusive curriculum is one that is representative of diverse individuals. Providing inclusive curricula to individuals in educational settings may increase their exposure to minority groups and in turn improve attitudes. Researchers have concluded that sexual minority individuals feel higher levels of inclusion and greater perceived safety at school when there are inclusive curriculum materials (i.e., materials which include sexual minority individuals; Kosciw et al., 2018). However, there is a gap in the research on how an inclusive curriculum impacts those who are heterosexual. Therefore, it is believed that by including sexual minority individuals throughout the formal curriculum materials, attitudes of heterosexual individuals may become more positive. In turn, this change in attitudes may diminish the higher levels of victimization toward sexual minority individuals and lead to more positive outcomes.

The primary purpose of the current study was to better understand the impact of an inclusive curriculum on heterosexual individuals' attitudes toward sexual minority individuals. I investigated changes in heterosexual individuals' attitudes after being exposed to curriculum materials that include individuals with sexual minority identities. Additionally, I sought to better understand how exposure to inclusive curricula may impact change in social justice attitudes, as these relate to the development of attitudes toward sexual minorities and may be predictive of discriminatory behaviors. I was also interested in identifying demographic characteristics that may moderate the relation between exposure to inclusive curriculum and attitude changes, such as gender, affiliation with a sorority or fraternity, and political affiliation in order to better understand who may hold these negative attitudes within the education system. Finally, I was interested in examining religiosity as a variable that may explain the process by which curricula influence attitude change.

Given the outlined purposes, the following hypotheses were proposed: 
$\mathrm{H}_{1}$ : Heterosexual individuals' attitudes toward sexual minority individuals will improve after exposure to an inclusive curriculum but will remain the same after exposure to heteronormative curriculum.

$\mathrm{H}_{2}$ : Heterosexual individuals' social justice attitudes will improve after exposure to an inclusive curriculum but will remain the same after exposure to heteronormative curriculum.

$\mathrm{H}_{3}$ : The relation between exposure to inclusive curriculum and attitudes toward sexual minority individuals will be moderated by gender, political affiliation, intrinsic religiosity, and affiliation with a campus sorority or fraternity. 


\section{CHAPTER III: METHODS}

\section{Participants}

Of the 161 participants who were recruited to participate in the study, 147 were included in the final analyses. Of these, 24 (16.30\%) individuals were first-year students, 28 (19\%) were sophomores, 51 (34.70\%) were juniors, and 44 (29.90\%) were seniors. Most participants identified as cisgender women $(111,75.50 \%)$ while the remaining $36(24.50 \%)$ identified as cisgender men. The age of participants ranged from 18 to $22(M=20.09, S D=1.15)$. Most participants identified as white $(112,76.20 \%)$, while $17(11.60 \%)$ identified as Asian, 10 identified as multiracial, 5 (3.40\%) identified as Latinx, 2 (1.40\%) identified as Black/African American, and $1(0.70 \%)$ identified as Middle Eastern. A majority of the sample indicated their political affiliation was best described as moderate $(59 ; 40.10 \%)$, while $35.40 \%$ (52) indicated liberal, 19\% (28) indicated conservative, and 5.40\% (8) indicated radical. Only $31(21.10 \%)$ participants were affiliated with a sorority or fraternity at their universities.

\section{Measures}

Participants completed questionnaires that were administered via Qualtrics, which is a widely used software to collect and store survey data. To obtain demographic information, each participant responded to open-ended questions regarding age, sex, gender identity, sexual orientation, and race/ethnicity. Participants were also asked to identify whether they were members of a sorority or fraternity on campus and to indicate which classification best described their political affiliation. These items are reported in Appendix A.

Duke University Religion Index. The Duke University Religion Index (DUREL; Koenig et al., 1997) is a 5-item measure developed by Koenig and colleagues (1997) that examines religiosity (see Appendix B). Specifically, the scale measures the organizational, 
nonorganizational, and intrinsic dimensions of religiosity. Prior research indicates that Cronbach's alphas for the three dimensions measured were acceptable, as they ranged from .78 to .91 (Koeing \& Bussing, 2010). The Intrinsic Religiosity subscale, which includes the last three questions of the larger measure, was the focus of the present study. This scale was selected, because it has been used in previous studies to examine the relation between religiosity and attitudes toward sexual minority individuals (Deese \& Dawson, 2013). The Cronbach's alpha for this subscale was acceptable at .95 .

Lesbian, Gay, and Bisexual Knowledge and Attitudes Scale for Heterosexuals. The Lesbian, Gay, and Bisexual Knowledge and Attitudes Scale for Heterosexuals (LGB-KASH; Worthington et al., 2005) is a 28 -item measure that examines dimensions of attitudes heterosexual individuals hold toward sexual minority individuals (see Appendix C). Participants responded to items on a 6-point Likert scale ranging from 1 ("very uncharacteristic of me or my views") to 6 ("very characteristic of me or my views"). Analyses in the initial validation of the measure yielded five factors (i.e., Hate, LGB Knowledge, Religious Conflict, LGB Civil Rights, and Internalized Affirmativeness). Cronbach's alphas for the five factors were acceptable, as they ranged from .70 to .89 (Raju et al., 2018). For the purpose of the current study, the Hate and Civil Rights Attitudes subscales were of primary interest. Cronbach's alphas for factors included in the present study across pretest and posttest were variable. The Rights alphas were acceptable and pretest (.73) and posttest (.81), whereas the Hate factor should be interpreted with caution, as the Cronbach's alphas yielded at pretest (.47) and posttest (.68) were inconsistent with those reported in the initial validation of the scale.

Social Justice Scale. The Social Justice Scale (SJS; Torres-Harding et al., 2012) is a 24item measure developed by Torres-Harding and colleagues (2012) that examines social justice 
attitudes and related behaviors (see Appendix D). Participants responded to items on a 7-point Likert scale ranging from 1 (“disagree strongly") to 7 (“agree strongly"). Analyses in the initial validation of the measure yielded 4 factors (i.e., Social Justice Attitudes, Social Justice Perceived Behavioral Control, Social Justice Subjective Norms, and Social Justice Behavioral Intentions).

For the purpose of the current study, the Social Justice Attitudes subscale was of primary interest. Cronbach's alphas for this factor were acceptable (.92) for both pretest and posttest.

\section{Procedure and Design}

Following approval from the Institutional Review Board (IRB), I recruited participants utilizing the university's mass email tool. I also sent emails to the student leaders of registered student organizations (RSOs) at universities across the United States and asked that they share the invitation to participate with their organizations' members. Upon providing consent, participants completed Study 1 by responding to demographic items and completing the DUREL (Koenig et al., 1997), LGB-KASH (Worthington et al., 2005), and SJS (Torres-Harding et al., 2012). Participants were then asked to indicate whether they would like to be entered in a drawing for a chance to win 1 of $4 \$ 20$ gift cards. Lastly, participants indicated whether they would like to be notified about additional unrelated research opportunities conducted by the same researcher, which was the method used to gather a pool of potential participants for Study 2.

When recruiting possible participants for Study 2, the researcher contacted participants from Study 1 who were between the ages of 18 and 22, were enrolled as an undergraduate student, identified as heterosexual, and indicated they were interested in being contacted for

future research at the end of Study 1. Based on these inclusionary criteria, 659 participants were invited to participate in Study 2. Participants were told that the purpose of this 3 -week study was 
to examine the math performance of college students. Those who elected to participate then received emails with links to the surveys for Study 2 for three consecutive weeks. Participants were randomly assigned to conditions (i.e., inclusive materials or heteronormative materials) using the Qualtrics randomizer function.

After consenting to participate each week, participants were presented with 10 math story problems one at a time and were prompted to complete them as quickly as possible. Some participants were exposed to math story problems that included only heterosexual characters while others were exposed to math story problems that included sexual minority individuals. The sexual orientation of a character was represented through descriptions of a person's relationship within the story problem (see Appendix E). These story problems were obtained from a website for teachers to share math assignments. Each of the story problem was at the eighth-grade level and included basic math functions (e.g., addition, subtraction, multiplication, division, fractions, etc.). Participants were provided feedback about the correct answer to each story problem. This was used as a way to ensure that participants remained under the impression that the purpose of the study was related to the distractor: college students' math skills. Upon completion of the math story problems during the third week, participants were prompted to complete the $L G B$ KASH (Worthington et al., 2005) and SJS (Torres-Harding, 2012) a second time. Participants were eligible to receive compensation up to $\$ 15$ in gift cards for completing these 3 surveys (i.e., $\$ 5$ per survey) and to enter a raffle for an iPad mini. Participants were then debriefed, as they were told the true purpose of the study and that Study 2 was related to Study 1. Lastly, participants provided consent to include their data in the analyses. 


\section{CHAPTER IV: RESULTS}

\section{Preliminary Analyses}

To facilitate analysis, the data were cleaned, and preliminary analyses were conducted. Specifically, condition assignment was coded such that participants who received inclusive materials were coded as 1 and those who were exposed to heteronormative materials were coded as a 2. Gender was coded as 1 for participants reporting identification as a woman and 2 for anyone who identified as a man, as articipants in the study self-reported only "man" and "woman" when asked to self-describe their gender, while sorority/fraternity was coded as a 1 for those who were affiliated with a group and 2 for those who were not. Ratings on the Political Affiliation and Intrinsic Religiosity subscales were coded as 1 for not conservative or low levels of religiosity (i.e., ratings of less than 3 ) and 2 for conservative or high levels of religiosity (i.e., ratings of 3 or greater). The Civil Rights Attitudes and Hate subscale scores for the LGB-KASH (Worthington et al., 2005) and Attitudes subscale score for the SJS (Torres-Harding et al., 2012) were computed by adding items that contributed to each factor in the original studies and then

dividing by the total number of items included. Respective means, standard deviations, and measures of normality for the $L G B-K A S H$ (Worthington et al., 2005) and SJS (Torres-Harding et al., 2012) subscales are displayed Table 1. As depicted by the results displayed in Table 1, several of the subscales were highly skewed meaning that normality should be considered when interpreting the results.

Independent Samples t-tests were conducted to assess group differences in $L G B-K A S H$ (Worthington et al., 2005) and SJS (Torres-Harding et al., 2012) pre-test scores to ensure that random assignment was effective. Based on the results of these analyses, no significant group differences exist between those who received the inclusive materials and those who received the 
heteronormative materials for all subscales on both the $L G B-K A S H$ (Worthington et al., 2005) and the SJS (Torres-Harding et al., 2012; see Table 2). Two-tailed Pearson correlations were conducted to assess associations between variables. As depicted in Table 3, subscales were significantly correlated for all pretest and posttest measures on both the LGB-KASH (Worthington et al., 2005) and SJS (Torres-Harding et al., 2012). Additionally, the Intrinsic Religiosity of the DUREL (Koenig et al., 1997) subscale was significantly correlated with all pretest and posttest subscales except for the Hate posttest measure. Because the Hate subscale was no longer significant at post-tetst it is possible that the curriculum may no thave been enough to enact change. Further implications are examined in the discussion section of this paper.

\section{Primary Analyses}

To test hypotheses, I ran Repeated Measures of Analyses of Variance (RM-ANOVA) to examine the effects of condition assignment (i.e., inclusive or heteronormative curricula materials) and potential moderators on changes in attitudes toward sexual minority individuals and social justice attitudes from pretest to posttest. I was primarily interested in the Civil Rights Attitudes (i.e., beliefs about civil rights of sexual minority individuals) and Hate (i.e., attitudes about avoidance, self-consciousness, hatred, and violence toward sexual minority individuals) subscales of the LGB-KASH (Worthington et al., 2005) and the Attitudes Toward Social Justice (i.e., social justice values, attitudes, and social justice related behaviors) of the SJS (TorresHarding et al., 2012). I entered subscales of the $L G B-K A S H$ (Worthington et al., 2005) and $S J S$ (Torres-Harding et al., 2012) as a within-in subjects variable for both pretest and posttest (i.e., time one and time two) and condition variable along with each potential moderator (i.e., gender, political affiliation, religiosity, and Greek affiliation) as the between-subjects factor. Because I 
was interested in several moderators (i.e., gender, political affiliation, religiosity, and Greek affiliation), I conducted four separate RM-ANOVAs.

Relevant to hypotheses 1 and 2, no significant changes in attitudes toward sexual minority individuals or social justice emerged from pre- to post-test given condition assignment, as these hypotheses were not supported. This was examined via the time by condition interaction effect, as displayed in Table 4. Hypothesis 3 concerned changes in attitudes toward sexual minority individuals and social justice based on condition assignment from pretest to posttest given gender, political affiliation, sorority or fraternity affiliation, and intrinsic religiosity as moderators. Examination of the within-subjects interactions indicate that none of these variables surfaced as significant moderators, as depicted in Table 4. Because there were no significant resultst, no additiotnal analyses were conducted. 


\section{CHAPTER V: DISCUSSION}

The purpose of the present study was to understand the impact of inclusive curriculum materials on attitudes toward sexual minority individuals and social justice, as well as what personal identities may impact this relation. In particular, the following hypotheses were offered:

$\mathrm{H}_{1}$ : Heterosexual individuals' attitudes toward sexual minority individuals will improve after exposure to an inclusive curriculum but will remain the same after exposure to heteronormative curriculum.

$\mathrm{H}_{2}$ :Heterosexual individuals' social justice attitudes will improve after exposure to an inclusive curriculum but will remain the same after exposure to heteronormative curriculum.

$\mathrm{H}_{3}$ : The relation between exposure to inclusive curriculum and attitudes toward sexual minority individuals will be moderated by gender, political affiliation, intrinsic religiosity, and affiliation with a campus sorority or fraternity.

Previous researchers have found that there are positive effects of inclusive curricula on individuals who identify as sexual minority individuals. Specifically, Kosciw and colleagues (2018) concluded that students who attend schools utilizing inclusive curricula experience less frequent victimization, hear fewer derogatory remarks, feel safer overall, and have higher levels of academic achievement. While this study provides insight into the positive impact of these curricula on students who identify as sexual minority individuals, the researchers did not address how the use of inclusive curricula impacts students not holding minoritized sexual orientation identities in schools. With recent policy changes that require the use of inclusive curricula and the alarming rates of victimization toward non-heterosexual individuals across settings (Kosciw et al., 2018; Dashow; 2018, Herek; 2009; Rey \& Gibson, 1997), I aimed to better understand 
how inclusive curricula materials could be utilized to improve attitudes toward sexual minority individuals and in turn diminish occurrences of victimization. I thought that inclusive curricula could be the drive behind this improvement in attitudes, as previous researchers have found that repeated exposure to both images of and information about racial and gender minority groups leads to more favorable attitudes (Flores et al., 2018; Zebrowitz et al., 2008).

The hypotheses of the current study were not supported, as individuals' attitudes toward sexual minority individuals and social justice attitudes were not significantly different from pretest to posttest given the materials they viewed. Additionally, gender, political affiliation, and affiliation with a sorority or fraternity did not significantly impact the relation between exposure to inclusive materials and attitudes. In other words, when participants were presented with math story problems (i.e., curricula materials) that included sexual minority individuals, participants' attitudes about social justice and towards sexual minority individuals did not demonstrate any significant changes when compared to those who were exposed to math story problems including only heterosexual individuals, regardless of personal variables like gender, political affiliations, sorority or fraternity involvement, or level of intrinsic religiosity.

\section{Limitations and Future Directions}

The current study had several limitations worth noting. First, all information from participants was gathered through self-report and collected electronically. Given the reliance on self-report data and the study's focus on issues of social justice, it is possible participants may have provided responses that they may have found more socially desirable on the measures of attitudes. In retrospect, I could have utilized a social desirability measure to control for this. Further, because participants completed the surveys and were exposed to the inclusive curricula electronically it is impossible to know how much they attended to each question or the math 
story problems that were being used as the control and experimental conditions. I attempted to address participants quickly reviewing the story problems by providing feedback about correct responses for each problem presented. I was specifically hoping to create the impression that getting the correct answer was important so that participants would attend well to each item. Future researchers could use behavioral observations to measure attitudes instead of scales, as previous researchers have linked discriminatory behaviors to attitudes to sexual minority individuals (Morrison \& Morrison, 2011). Additionally, future researchers may seek to provide exposure to curricula materials in-person or utilize a method to measure how long a participant spends attending to curriculum materials. In the future, tracking participants performance on the math story problems would allow researchers to determine if there are differences in levels of change based on performance.

Both internal and external validity of the present study raise concern and should be considered additional limitations. Regarding internal validity, there are unknown factors that were not accounted for that may have impacted the relation between one's attitudes and the use of inclusive curricula materials. For example, the present student asked participants to self-report several personal characteristics (i.e., gender, political affiliation, intrinsic religiosity, and affiliation with a sorority or fraternity) that have been shown to impact attitudes toward sexual minority individuals but there are many other variables that were not accounted for in this study, such as personal relationships with others who identify as a sexual minority individuals, parental beliefs, and prior education about sexual minority individuals (Hans et al., 2012). Because these factors were not measured, it is impossible to say whether one of these acted as a confounding variable. Future researchers may consider collecting data to provide context as to how these 
additional factors may impact predisposed attitudes or how they may moderate changes in attitudes overtime due to experimental manipulation.

Relevant to external validity, there are some concerns about the final sample. Specifically, the demographics of the sample make it difficult to generalize to the greater population due to a lack of variance in age, race and ethnicity, gender, and geographic location, among other homogenous characteristics. All participants in the study were between the ages of 18 and 22, as that was the target population I recruited. Aside from age, I made efforts to recruit individuals from varied diverse backgrounds and beliefs by sending recruitment emails to more than 17,500 individuals from at least 40 universities across 26 states. Because of the small sample size, moderators were dichotomized and analyzed as main effectst rather than interaction effects. In an effort to increase the response rate I sent multiple emails reminding individuals of the invitation to participate. Regardless of these efforts, the final sample included only 147 individuals, most of identified as cisgender, white women who were enrolled at a Midwestern Predominately White Institution and were not associated with a university sorority or fraternity. Future researchers should focus on recruiting a sample that would be more representative of the greater population. Given what we know about prior research, this may produce more variance in attitudes and allow for more room for change explained by exposure to inclusive curricula materials. Additionally, future researchers may wish to include individuals of different ages in order to assess generational differences, as previous research has found individuals who belong to older generations hold more negative attitudes toward sexual minority individuals than those who belong to younger generations (Newport, 2018). Lastly, past researchers have found that college educated individuals hold more positive attitudes toward sexual minority individuals, so it may be beneficial for future researchers to examine the effects of inclusive curricula materials 
on individuals who are not currently enrolled or have never been enrolled in a college or university (Fingerhut, 2011).

Based on the demographic data collected, I predicted that the attitudes toward sexual minority individuals held by those included in the sample were positive toward sexual minority individuals at pretest, which I found to be true. This positive trend would not be expected assuming a normal distribution. Specifically, all subscales of primary interests were positively skewed at pretest and posttest. Given reports of attitudes at pretest, there was little room for attitudes to become more positive. Additionally, the significant correlations between the subscales used to assess attitudes suggest that each of these subscales were not necessarily measuring a unique construct and that the different means for measuring attitude. In the future, researchers may consider selectting measures that may be more sensitive to change. In conclusion, hypotheses that individuals exposed to inclusive curriculum materials would have improved attitudes toward sexual minority individuals from pretest to posttest and that several factors would moderate the relation between exposure and attitudes were not supported. Regardless, future research in this area is warranted. Future researchers may consider recruiting a more diverse set of participants. Targeted recruitment may allow for a more variable population and may include individuals which are more likely to hold the most negative attitudes. Future researchers may also address this by evaluating attitudes in a different manner and implementing a social desirability scale. By selecting a scale that is more subtle or not as subject to social desirability may account for this limitation in future research. Examples may include observing behaviors or recording instances of microaggressions as means to measure attitudes. 


\section{REFERENCES}

Albarracin, D., Johnson, B. T., \& Zanna, M. P. (2005). The handbook of attitudes. Mahwah, NJ: Lawrence Erlbaum.

Alsubai, M. A. (2015). Hidden Curriculum as One Current Issue of Curriculum. Journal of Education and Practice.

Almeida, J., Johnson, R. M., Corliss, H. L., Molnar, B. E., \& Azrael, D. (2009). Emotional distress among LGBT youth: The influence of perceived discrimination based on sexual orientation. Journal of youth and adolescence, 38(7), 1001-1014. doi:10.2105/AJPH.2006.099473.

American Psychological Association. (2015). APA dictionary of psychology (2 ${ }^{\text {nd }}$ ed.). Washington, DC.

American Psychological Association. (2008). Answers to your questions: For a better understanding of sexual orientation and homosexuality. Washington, DC: Author. [Retrieved from www.apa.org/topics/lgbt/orientation.pdf.

Badgett, L., \& Frank, J. (Eds.). (2007). Sexual orientation discrimination: An international perspective. Routledge.

Banks, B. M., \& Cicciarelli, K. (2019). Microaggressive classroom language and diminished cognitive functioning. Journal for Multicultural Education. doi: 10.1108/JME-05-20190039.

Berrill, K. T. (1990). Anti-gay violence and victimization in the United States: An overview. Journal of Interpersonal Violence, 5(3), 274-294. doi: $10.1177 / 088626090005003003$. 
Calzo, J. P., \& Ward, L. M. (2009). Media exposure and viewers' attitudes toward homosexuality: Evidence for mainstreaming or resonance?. Journal of Broadcasting \& Electronic Media, 53(2), 280-299. doi: 10.1080/08838150902908049.

Carlsson, M., \& Eriksson, S. (2017). Do attitudes expressed in surveys predict ethnic discrimination?. Ethnic and Racial Studies, 40(10), 1739-1757. doi: 10.1080/01419870.2016.1201580.

Carruthers, P. (2018). Implicit versus explicit attitudes: Differing manifestations of the same representational structures?. Review of Philosophy and Psychology, 9(1), 51-72.

Castro, I. E., \& Sujak, M. C. (2014). “Why can’t we learn about this?” Sexual minority students navigate the official and hidden curricular spaces of high school. Education and Urban Society, 46(4), 450-473. doi: 0.1177/0013124512458117.

Crano, W. D., \& Prislin, R. (Eds.). (2008). Frontiers of social psychology. Attitudes and attitude change. New York, NY, US: Psychology Press.

Chesir-Teran, D., \& Hughes, D. (2009). Heterosexism in high school and victimization among lesbian, gay, bisexual, and questioning students. Journal of Youth and Adolescence, 38(7), 963-975. doi:10.1037/0022-3514.51.6.1173.

Cormier Castaneda, Megan C., "The Relationship of Spirituality, Religiosity and Attitudes toward Lesbians and Gay Men Among Students at a Faith-Based Institution" (2019). Doctor of Psychology (PsyD). 260. https://digitalcommons.georgefox.edu/psyd/260

Dashow, J. (2018). New FBI Statistics Show Alarming Increase in Number of Reported Hate Crimes. Retrieved from https://www.hrc.org/blog/new-fbi-statistics-show-alarmingincrease-in-number-of-reported-hate-crimes.

Davis, J. Q. (2004). Anger, Aggression, and Adolescents. New York: Pantheon Books. 
DePalma, R., \& Atkinson, E. (2010). The nature of institutional heteronormativity in primary schools and practice-based responses. Teaching and Teacher Education, 26(8), 16691676. doi: 10.1016/j.tate.2010.06.018.

Egan, K. (2003). Retrospective on "What is Curriculum?". Journal of the Canadian Association for Curriculum Studies, 1(1).

Fingerhut, A. W. (2011). Straight Allies: What Predicts Heterosexuals' Alliance With the LGBT Community? 1. Journal of Applied Social Psychology, 41(9), 2230-2248. doi: 10.1111/j.1559-1816.2011.00807.

Finlay, B., \& Walther, C. S. (2003). The relation of religious affiliation, service attendance, and other factors to homophobic attitudes among university students. Review of Religious Research, 370-393. doi: 10.2307/3512216.

Flores, A. R., Haider-Markel, D. P., Lewis, D. C., Miller, P. R., Tadlock, B. L., \& Taylor, J. K. (2018). Challenged expectations: Mere exposure effects on attitudes about transgender people and rights. Political Psychology, 39(1), 197-216. doi: 10.1111/pops.12402.

Gallup. (2019). Gay and Lesbian Rights. Retrieved from https://news.gallup.com/poll/1651/gaylesbian-rights.aspx.

Galupo, M. P., \& Resnick, C. A. (2016). Experiences of LGBT microaggressions in the workplace: Implications for policy. In Sexual orientation and transgender issues in organizations(pp. 271-287). Springer, Cham.

Gay and Lesbian Alliance Against Defamation (GLAAD). (2019). Accelerating Acceptance 2019. Retrieved from https://www.glaad.org/sites/default/files/Accelerating\% 20Acceptance\%202019.pdf. 
Giroux, H. A., \& Penna, A. N. (1979). Social education in the classroom: The dynamics of the hidden curriculum. Theory \& Research in Social Education, 7(1), 21-42.

Glick, S. N., Cleary, S. D., \& Golden, M. R. (2015). Brief report: increasing acceptance of homosexuality in the United States across racial and ethnic subgroups. JAIDS Journal of Acquired Immune Deficiency Syndromes, 70(3), 319-322. doi:

10.1097/QAI.0000000000000740.

GLSEN. (2019). “No Promo Homo Laws.” Retrieved from https:/www.glsen.org/article/statemaps.

Goodhand, M., \& Brown, K. M. (2016). Heteronormativity in Elementary Schools: The Hidden and Evaded Curricula of Gender Diversity. International Journal of School and Cognitive Psychology, 3(3), 1-15.

Grush, J. E. (1976). Attitude formation and mere exposure phenomena: A nonartifactual explanation of empirical findings. Journal of Personality and Social Psychology, 33(3), 281-290. doi: 10.1037/0022-3514.33.3.281

Hans, J. D., Kersey, M., \& Kimberly, C. (2012). Self-perceived origins of attitudes toward homosexuality. Journal of Homosexuality, 59(1), 4-17.

Harbaugh, E., \& Lindsey, E. W. (2015). Attitudes toward homosexuality among young adults: Connections to gender role identity, gender-typed activities, and religiosity. Journal of homosexuality, 62(8), 1098-1125.

Harris, J., \& White, V. (2013). A Dictionary of Social Work and Social Care. Oxford University Press. p. 335. Retrieved June, 2019. 
Hawker, D. \& Boulton, M. (2000). Twenty Years’ Research on Peer Victimization and Psychosocial Maladjustment: A Meta-analytic Review of Cross-sectional Studies. Journal of Child Psychology and Psychiatry. 41. 441-455. 10.1111/1469-7610.00629.

Herek, G. M. (2000). The Psychology of Sexual Prejudice. American Psychological Society, $9(1)$.

Herek, G. M. (2009). Hate crimes and stigma-related experiences among sexual minority adults in the United States: Prevalence estimates from a national probability sample. Journal of interpersonal violence, 24(1), 54-74.

Herek, G. M., \& Capitanio, J. P. (1995). Black heterosexuals' attitudes toward lesbians and gay men in the United States. Journal of Sex Research, 32(2), 95-105.

Hogg, M., \& Vaughan, G. (2005). Social Psychology (4th edition). London: Prentice-Hall.

Holland, L., Matthews, T. L., \& Schott, M. R. (2013). “That's so gay!” exploring college students' attitudes toward the LGBT population. Journal of Homosexuality, 60(4), 575595.

Human Rights Campaign. (2020). “Glossary of Terms.” Retrieved from https://www.hrc.org/resources/glossary-of-terms.

Jaccard, J., King, G. W., \& Pomazal, R. (1977). Attitudes and behavior: An analysis of specificity of attitudinal predictors. Human Relations, 30(9), 817-824.

Johnson, R. C., Thomson, C. W., \& Frincke, G. (1960). World values, word frequency, and visual duration thresholds. Psychological Review, 67, 332-342.

Kann, L., McMannus, T., Harris, W.A., et al. (2017). Youth Risk Behavior Surveillance-United States, 2017. Retrieved from https://www.cdc.gov/mmwr/volumes/67/ss/ss6708a1.htm Kelly, A. V. (2009). The curriculum: Theory and practice. Sage. 
Kite, M. E., \& Bryant-Lees, K. B. (2016). Historical and contemporary attitudes toward homosexuality. Teaching of Psychology, 43(2), 164-170.

Kite, M. E., \& Whitley Jr, B. E. (1996). Sex differences in attitudes toward homosexual persons, behaviors, and civil rights a meta-analysis. Personality and Social Psychology Bulletin, $22(4), 336-353$.

Koenig, H., Parkerson Jr, G. R., \& Meador, K. G. (1997). Religion index for psychiatric research.

Kosciw, J. G., Greytak, E. A., Zongrone, A. D., Clark, C. M., \& Truong, N. L. (2018). The 2017 National School Climate Survey: The Experiences of Lesbian, Gay, Bisexual, Transgender, and Queer Youth in Our Nation's Schools. Gay, Lesbian and Straight

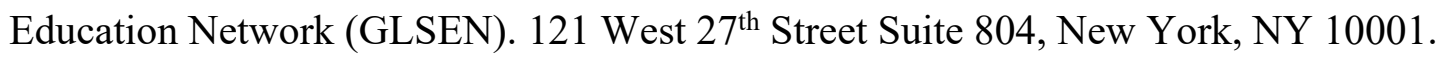

Kraus, S. J. (1995). Attitudes and the prediction of behavior: A meta-analysis of the empirical literature. Personality and social psychology bulletin, 21(1), 58-75.

LGBT Demographic Data Interactive. (January, 2019). Los Angeles, CA: The Williams Institute, UCLA School of Law.

Mabwe, N. (2015). Curriculum design and society "a hand in glove" relationship. Sciences: Basic and Applied Research, 24(4), 207-220.

MacGillivray, I. K. (2000). Educational equity for gay, lesbian, bisexual, transgendered, and queer/questioning students: The demands of democracy and social justice for America's schools. Education and Urban Society, 32(3), 303-323.

Martin, J. R. (1976). What should we do with a hidden curriculum when we find one?. Curriculum Inquiry, 6(2), 135-151. 
Mazur, M. A., \& Emmers-Sommer, T. M. (2003). The effect of movie portrayals on audience attitudes about nontraditional families and sexual orientation. Journal of homosexuality, 44(1), 157-181.

McCarthy, J. (2019). Gallup First Polled on Gay Issues in '77. What Has Changed? Retrieved from https://news.gallup.com/poll/258065/gallup-first-polled-gay-issues-changed.aspx.

McDaniels, M. (2017). Cultivating Inclusive Classrooms: Inclusive Curriculum Design. Retrieved from https:/iteach.msu.edu/iteachmsu/groups/iteachmsu/stories/117.

Morrison, M. A., \& Morrison, T. G. (2011). Sexual orientation bias toward gay men and lesbian women: Modern homonegative attitudes and their association with discriminatory behavioral intentions. Journal of Applied Social Psychology, 41(11), 2573-2599.

Nadal, K. (2008). Preventing racial, ethnic, gender, sexual minority, disability, and religious microaggressions: Recommendations for promoting positive mental health. Prevention in Counseling Psychology: Theory, Research, Practice, and Training, 2(1), 22-27.

Nadal, K. L., Wong, Y., Griffin, K. E., Davidoff, K., \& Sriken, J. (2014). The adverse impact of racial microaggressions on college students' self-esteem. Journal of college student development, 55(5), 461-474.

National Association of School Psychologists (2006). Position statement on gay, lesbian, bisexual, transgender, and questioning (GLBTQ) youth (formerly sexual minority youth). Retrieved from http://www.safeschoolscoalition.org/RG-PositionStatement-NASP.html.

National Center for Education Statistics. (2019). Back to school statistics, retrieved from https://nces.ed.gov/fastfacts/display.asp?id=372.

Newport, F. (2018). In U.S., Estimates of LGBT Populations Rises to 4.5\%. Retrieved from https://news.gallup.com/poll/234863/estimate-lgbt-population-rises.aspx. 
Olson, J. M., Vernon, P. A., Harris, J. A., \& Jang, K. L. (2001). The heritability of attitudes: a study of twins. Journal of personality and social psychology, 80(6), 845.

Pilkington, N. W., \& D’Augelli, A. R. (1995). Victimization of lesbian, gay, and bisexual youth in community settings. Journal of Community Psychology, 23(1), 34-56.

Poteat, V. P. (2007). Peer group socialization of homophobic attitudes and behavior during adolescence. Child development, 78(6), 1830-1842.

Raju, D., Beck, L., Azuero, A., Azuero, C., Vance, D., \& Allen, R. (2018). A comprehensive psychometric examination of the lesbian, gay, and bisexual knowledge and attitudes scale for heterosexuals (LGB-KASH), Journal of Homosexuality, DOI: 10.1080/00918369.2018.1491705.

Rey, A. M. \& Gibson, P. R. (2008). Beyond high school: Heterosexuals’ self-reported antigay/lesbian behaviors and attitudes. Journal of Gay and Lesbian Social Services, 7(4), 6584. DOI: 10.1300/J041v07n04_05.

Rhodes, G., Halberstadt, J., \& Brajkovich, G. (2001). Generalization of mere exposure effects to averaged composite faces. Social Cognition, 19(1), 57-70.

Salomaa, A. C., \& Matsick, J. L. (2019). Carving sexuality at its joints: Defining sexual orientation in research and clinical practice. Psychological Assessment, 31(2), 167.

Savin-Williams, R. C. (2014). An exploratory study of the categorical versus spectrum nature of sexual orientation. The Journal of Sex Research, 51(4), 446-453.

Sell, R. L. (1997). Defining and measuring sexual orientation: A review. Archives of sexual behavior, 26(6), 643-658. 
Schwartz, S. (2019). Four States Now Require Schools to Teach LGBT History. Retrieved from http://blogs.edweek.org/teachers/teaching_now/2019/08/four_states_now_require_school s_to_teach_lgbt_history.html.

Smith, P. K., Dijksterhuis, A., \& Chaiken, S. (2008). Subliminal exposure to faces and racial attitudes: Exposure to Whites makes Whites like Blacks less. Journal of Experimental Social Psychology, 44(1), 50-64.

Stewart, L. D., \& Perlow, R. (2001). Applicant race, job status, and racial attitude as predictors of employment discrimination. Journal of Business and Psychology, 16(2), 259-275.

Toombs, W. E., \& Tierney, W. G. (1993). Curriculum definitions and reference points. Journal of Curriculum and Supervision, 8, 175-175.

Torres-Harding, S. R., Siers, B., \& Olson, B. D. (2012). Development and psychometric evaluation of the Social Justice Scale (SJS). American journal of community psychology, $50(1-2), 77-88$.

United States Department of Education. (2008). Structure of the U.S. Education System: Curriculum and Content Standards. Retrieved from http://www.ed.gov/international/usnei/edlite-index.html.

Van Anders, S. M. (2015). Beyond sexual orientation: Integrating gender/sex and diverse sexualities via sexual configurations theory. Archives of Sexual Behavior, 44(5), $1177-$ 1213.

Waldo, C. R., Hesson-McInnis, M. S., \& D’Augelli, A. R. (1998). Antecedents and consequences of victimization of lesbian, gay, and bisexual young people: A structural model comparing rural university and urban samples. American Journal of Community Psychology, 26(2), 307-334. https://doi.org/10.1023/A:1022184704174 
Walton, G. (2005). The hidden curriculum in schools: Implications for lesbian, gay, bisexual, transgender, and queer youth. Alternate Routes, 21, 18-39.

Wiles, J. (2008). Leading curriculum development. Corwin Press.

Woodford, M. R., Silverschanz, P., Swank, E., Scherrer, K. S., \& Raiz, L. (2012). Predictors of heterosexual college students' attitudes toward LGBT people. Journal of LGBT Youth, 9(4), 297-320.

Worthen, M. G. (2014). Blaming the Jocks and the Greeks?: Exploring Collegiate Athletes' and Fraternity/Sorority Members’ Attitudes Toward LGBT Individuals. Journal of College Student Development, 55(2), 168-195.

Worthington, R. L., Dillon, F. R., \& Becker-Schutte, A. M. (2005). Development, reliability, and validity of the lesbian, gay, and bisexual knowledge and attitudes scale for heterosexuals (LGB-KASH). Journal of Counseling Psychology, 52(1), 104-118. DOI: 10.1037/00220167.52.1.104.

Zajonc, R. B. (1968). Attitudinal effects of mere exposure. Journal of personality and social psychology, 9(2p2), 1.

Zebrowitz, L. A., White, B., \& Wieneke, K. (2008). Mere exposure and racial prejudice: Exposure to other-race faces increases liking for strangers of that race. Social cognition, 26(3), 259-275.

Zimbardo, P. G., \& Leippe, M. R. (1991). The psychology of attitude change and social influence. Mcgraw-Hill Book Company. 


\section{APPENDIX A: DEMOGRAPHIC QUESTIONNAIRE}

Please answer the following questions.

What is your age?

What is your sex?

What is your gender identity?

What is your sexual orientation?

What is your race/ethnicity?

Are you part of a Greek Life (e.g., a member of a sorority or fraternity)?

(1) Yes

(2) No

Which best describes your political affiliation?

(1) Radical

(2) Liberal

(3) Moderate

(4) Conservative

(5) Ultraconservative 


\section{APPENDIX B: DUKE UNIVERSITY RELIGION INDEX}

Please give your honest rating about the degree to which each statement is characteristic of you.

How often do you attend church or other religious meetings?
(1) Never
(2) Once a year or less
(3) A few times a year
(4) A few times a month
(5) Once a week
(6) More than once a week

How often do you spend time in private religious activities, such as prayer, meditation, or Bible study?
(1) Rarely or never
(2) A few times a month
(3) Once a week
(4) Two or more times a week
(5) Daily
(6) More than once a day

In my life, I experience the presence of the Divine (i.e., God).

(1) Definitely not true

(2) Tends not to be true

(3) Unsure

(4) Tends to be true

(5) Definitely true of me

My religious beliefs are what really lie behind my whole approach to life.

(1) Definitely not true

(2) Tends not to be true

(3) Unsure

(4) Tends to be true

(5) Definitely true of me

I try hard to carry my religion over into all other dealings in life.

(1) Definitely not true

(2) Tends not to be true

(3) Unsure

(4) Tends to be true

(5) Definitely true of me 


\section{APPENDIX C: LESBIAN, GAY, AND BISEXUAL KNOWLEDGE AND ATTITUDES \\ SCALE FOR HETEROSEXUALS}

Please use the scale below to respond to the following items. Select the number that indicates the extent to which each statement is characteristic or uncharacteristic of you or your views. Please try to respond to every item.

$\begin{array}{cccccc}1 & 2 & 3 & 4 & 5 & 6 \\ \text { (Very Uncharacteristic) } & & & & & \text { (Very Characteristic) }\end{array}$

\section{NOTE: LGB = Lesbian, Gay, or Bisexual}

1. I feel qualified to educate others about how to be affirmative regarding LGB issues.

2. I have conflicting attitudes or beliefs about LGB people.

3. I can accept LGB people even thought I condemn their behavior

4. It is important to me to avoid LGB people.

5. I could educate others about the history and symbolism behind the "pink triangle."

6. I have close friends who are LGB.

7. I have difficulty reconciling my religious views with my interest in being accepting of LGB people.

8. I would be unsure what to do or say if I met someone who is openly lesbian, gay, or bisexual.

9. Hearing about a hate crime against an LGB person would not bother me.

10. I am knowledgeable about the significance of the Stonewall Riot to the Gay Liberation Movement.

11. I think marriage should be legal for same sex couples.

12. I keep my religious views to myself in order to accept LGB people.

13. I conceal my negative views toward LGB people when I am with someone who doesn't share my views.

14. I sometimes think about being violent toward LGB people.

15. Feeling attracted to another person of the same sex would not make me uncomfortable.

16. I am familiar with the work of the National Gay and Lesbian Task Force.

17. I would display a symbol of gay pride (pink triangle, rainbow, etc.) to show support of the LGB community.

18. I would feel self-conscious greeting a known LGB person in a public place.

19. I have had sexual fantasies about members of my same sex.

20. I am knowledgeable about the history and mission of the PFLAG organization.

21. I would attend a demonstration to promote LGB civil rights.

22. I try not to let my negative beliefs about LGB people harm my relationships with lesbian, gay, or bisexual individuals.

23. Hospitals should acknowledge same sex partners equally to any other next of kin.

24. LGB people deserve the hatred they receive.

25. It is important to teach children positive attitudes toward LGB people. 
26. I conceal my positive attitudes toward LGB people when I am with someone who is homophobic.

27. Health benefits should be available equally to same sex partners as to any other couple.

28. It is wrong for courts to make child custody decisions based on a parent's sexual orientation. 


\section{APPENDIX D: SOCIAL JUSTICE SCALE}

Using the 7-point scale, please give your honest rating about the degree to which you personally agree or disagree with each statement. Please be as open and honest as you can; there are no right or wrong answers.
12
3
4
5
$6 \quad 7$

(Strongly Disagree)

(Strongly Agree)

1. I believe that it is important to make sure that all individuals and groups have a chance to speak and be heard, especially those from traditionally ignored or marginalized groups.

2. I believe that it is important to allow individuals and groups to define and describe their problems, experiences and goals in their own terms.

3. I believe that it is important to talk to others about societal systems of power, privilege, and oppression.

4. I believe that it is important to try to change larger social conditions that cause individual suffering and impede well-being.

5. I believe that it is important to help individuals and groups to pursue their chosen goals in life.

6. I believe that it is important to promote the physical and emotional well-being of individuals and groups.

7. I believe that it is important to respect and appreciate people's diverse social identities

8. I believe that it is important to allow others to have meaningful input into decisions affecting their lives.

9. I believe that it is important to support community organizations and institutions that help individuals and groups achieve their aims.

10. I believe that it is important to promote fair and equitable allocation of bargaining powers, obligations, and resources in our society.

11. I believe that it is important to act for social justice.

12. I am confident that I can have a positive impact on others' lives.

13. I am certain that I possess an ability to work with individuals and groups in ways that are empowering.

14. If I choose to do so, I am capable of influencing others to promote fairness and equality.

15. I feel confident in my ability to talk to others about social injustices and the impact of social conditions on health and well-being.

16. I am certain that if I try, I can have a positive impact on my community.

17. Other people around me are engaged in activities that address social injustices.

18. Other people around me feel that it is important to engage in dialogue around social injustices.

19. Other people around me are supportive of efforts that promote social justice.

20. Other people around me are aware of issues of social injustices and power inequalities in our society.

21. In the future, I will do my best to ensure that all individuals and groups have a chance to speak and be heard. 
22. In the future, I intend to talk with others about social power inequalities, social injustices, and the impact of social forces on health and well-being.

23. In the future, I intend to engage in activities that will promote social justice.

24. In the future, I intend to work collaboratively with others so that they can define their own problems and build their own capacity to solve problems. 


\section{APPENDIX E: CURRICULUM MATERIALS}

\section{Experimental Condition}

\section{Week 1}

1. Peter bought a bag of candy. He gave his husband $10 \%$ of the candy. He gave $1 / 2$ of what he had left to his friend, Joe, and then ate $1 / 2$ of the remaining 18 pieces of candy. How many pieces of candy were there to begin with?

2. John bought a shirt that was on sale for $25 \%$ off the original price. He had a coupon to take another $25 \%$ off the discounted price. If the final price was $\$ 16$, what was the price before the first discount.

3. Jess found 92 seashells on the beach. She gave $1 / 2$ to her friend and another 16 to her wife. How may seashells does she have left?

4. The school band is going to a competition. Five members play the flute. There are three times as many members who play the trumpet. There are eight fewer trombone players than trumpeters, and eleven more drummers than trombone players. There are twice as many members that play the clarinet as members that play the flute. There are four fewer tuba players than there are trombone players, but three more members play the French horn than play the trombone. The band director, his assistant, and six parent volunteers are also going. How many seats are needed on the bus?

5. Carter was driving to another state to see his boyfriend. Carter drove $1 / 4$ of the way in the morning and 1/8 of the way at night. The next day, when he woke up, what percentage of the trip did Carter have left to drive?

6. Katie buys a video game for her Xbox for $\$ 49.99$, a controller for $\$ 34.95$, and a walkthrough manual for $\$ 19.99$. The sales tax in her area is $8.25 \%$. What will the total cost of her purchase be?

7. Charlie builds decks for a living. He builds 14 standard decks in 3 weeks. How many decks can he build in 3 months?

8. Heather and her wife put $\$ 580$ into a savings account for one year. The rate of interest on the account was $6.5 \%$. How much was in the account at the end of that year?

9. Alyssa is making her girlfriend a cake for her birthday. The recipe calls for 6 cups of flour, she has already used 2 and 1/4. How many more does she need to add?

10. After eating at a restaurant, Tim, Jason, and Sally decided to divide the bill evenly. If each person paid $\$ 47$, what was the total of the bill?

\section{Week 2}

1. Yesterday, there were 11 bales of hay in the barn. Benny stacked more bales in the barn today. There are now 99 bales of hay in the barn. How many bales did he store in the barn?

2. Mike received a gift card to a sporting goods store from his boyfriend for his birthday. He bought a baseball glove, baseball, and a shirt which came to a total of $\$ 134.89$. He had $\$ 65.11$ on the gift card after these purchases. How much was on the card to begin with? 
3. There were 9 roses in the vase that Sara received from her wife. Sara cut some more roses from her flower garden. There are now 17 roses in the vase. How many roses did she cut?

4. David takes 12 hours to paint a house. If his husband helps, it takes him 5 hours. Without help, how long would it take Keith to finish the same job?

5. Nancy spent half of the money she earned babysitting going to the movies. She earned another $\$ 15$ walking a friend's dog. How much did she earn babysitting if she ended the week with $\$ 27.50$ ?

6. On Monday, 382 students went on a trip to the zoo. All 7 buses were filled, and 4 students had to travel in cars. How many students were on each bus?

7. Samantha sold half of her comic books and then her wife bought her 6 more. Now she has 62. How many did she have to begin with?

8. Joan had $\$ 219$ to spend on 7 books. After buying them she still had $\$ 16$. Assuming all books cost the same amount, how much did each cost?

9. Sean bought 4 new baseball trading cards to add to his collection. The next day his dog ate half of his collection. There are now 95 cards left. How many did he start with?

10. Oceanside Bike Rental Shop charges $\$ 17$ plus $\$ 6$ an hour for renting a bike. Nancy paid for her and her girlfriend to rent bikes. She paid a total of $\$ 70$. How many hours did they each ride bikes?

\section{Week 3}

1. 5 hockey pucks and 3 hockey sticks costs $\$ 95.85$. 1 hockey stick costs $\$ 30$. How much does 1 hockey puck cost?

2. An airline charges $\$ 153$ for each first-class ticket and $\$ 101$ for each coach ticket. There will be 139 passengers total. If $30 \%$ of the passengers composed fly first-class, how much money will the airline make?

3. John bought 6 shirts for his husband. For every shift he purchased, he got one for $30 \%$ off. If the normal price per shirt was $\$ 20$, how much money did John spend on his shopping trip?

4. Megan's sister is turning 48 in April. She is 3 times older than Megan's brother, John, and twice as old as Megan. How old is John?

5. Stacey and her wife have 77 books in their home library. Each of them bought the same number of books to add to their library this weekend at garage sales. They now have 91 books. How many books did they each buy?

6. After paying $\$ 9$ for a piece of pie for herself and her girlfriend, Jennifer has $\$ 55$ dollars left. How many more pieces of pie could she buy with this money?

7. Paul and his husband had 11 peaches left at their roadside fruit stand. They went to the orchard and picked more peaches to stock up for the afternoon crowd. They now have 172 peaches. How many did they pick?

8. There are 31 walnut trees currently in the park. Park workers will plant more trees Monday, Tuesday, and Wednesday this week. When workers are finished, there will be 94 trees. If they plant the same number of trees each day, how many will they plant on Monday?

9. Joy is baking a cake. The recipe calls for 1 and $1 / 4$ cups of sugar. If she has added $2 / 3$ cup, how much more does she need to add?

10. Brooke traveled to Houston by car to visit her wife's family. Going there took 9 hours, and the return trip lasted 5 hours. Brooke averaged a speed of 88 miles per hour returning. What was the average speed on the way there? 


\section{Control Condition}

\section{Week 1}

1. Peter bought a bag of candy. He gave his wife $10 \%$ of the candy. He gave $1 / 2$ of what he had left to his friend, Joe, and then ate $1 / 2$ of the remaining 18 pieces of candy. How many pieces of candy were there to begin with?

2. John bought a shirt that was on sale for $25 \%$ off the original price. He had a coupon to take another $25 \%$ off the discounted price. If the final price was $\$ 16$, what was the price before the first discount.

3. Jess found 92 seashells on the beach. She gave $1 / 2$ to her friend and another 16 to her husband. How may seashells does she have left?

4. The school band is going to a competition. Five members play the flute. There are three times as many members who play the trumpet. There are eight fewer trombone players than trumpeters, and eleven more drummers than trombone players. There are twice as many members that play the clarinet as members that play the flute. There are four fewer tuba players than there are trombone players, but three more members play the French horn than play the trombone. The band director, his assistant, and six parent volunteers are also going. How many seats are needed on the bus?

5. Carter was driving to another state to see his girlfriend. Carter drove $1 / 4$ of the way in the morning and $1 / 8$ of the way at night. The next day, when he woke up, what percentage of the trip did Carter have left to drive?

6. Katie buys a video game for her Xbox for $\$ 49.99$, a controller for $\$ 34.95$, and a walk-through manual for $\$ 19.99$. The sales tax in her area is $8.25 \%$. What will the total cost of her purchase be?

7. Charlie builds decks for a living. He builds 14 standard decks in 3 weeks. How many decks can he build in 3 months?

8. Heather and her husband put $\$ 580$ into a savings account for one year. The rate of interest on the account was $6.5 \%$. How much was in the account at the end of that year?

9. Alyssa is making her girlfriend a cake for her birthday. The recipe calls for 6 cups of flour, she has already used 2 and $1 / 4$. How many more does she need to add?

10. After eating at a restaurant, Tim, Jason, and Sally decided to divide the bill evenly. If each person paid $\$ 47$, what was the total of the bill?

\section{Week 2}

1. Yesterday, there were 11 bales of hay in the barn. Benny stacked more bales in the barn today. There are now 99 bales of hay in the barn. How many bales did he store in the barn?

2. Mike received a gift card to a sporting goods store from his girlfriend for his birthday. He bought a baseball glove, baseball, and a shirt which came to a total of $\$ 134.89$. He had $\$ 65.11$ on the gift card after these purchases. How much was on the card to begin with?

3. There were 9 roses in the vase that Sara received from her husband. Sara cut some more roses from her flower garden. There are now 17 roses in the vase. How many roses did she cut?

4. David takes 12 hours to paint a house. If his wife helps, it takes him 5 hours. Without help, how long would it take Keith to finish the same job? 
5. Nancy spent half of the money she earned babysitting going to the movies. She earned another $\$ 15$ walking a friend's dog. How much did she earn babysitting if she ended the week with $\$ 27.50$ ?

6. On Monday, 382 students went on a trip to the zoo. All 7 buses were filled, and 4 students had to travel in cars. How many students were on each bus?

7. Sam sold half of her comic books and then her husband bought her 6 more. Now she has 62 . How many did she have to begin with?

8. Joan had \$219 to spend on 7 books. After buying them she still had \$16. Assuming all books cost the same amount, how much did each cost?

9. Sean bought 4 new baseball trading cards to add to his collection. The next day his dog ate half of his collection. There are now 95 cards left. How many did he start with?

10. Oceanside Bike Rental Shop charges $\$ 17$ plus $\$ 6$ an hour for renting a bike. Nancy paid for her and her boyfriend to rent bikes. She paid a total of $\$ 70$. How many hours did they each ride bikes?

\section{Week 3}

1. 5 hockey pucks and 3 hockey sticks costs $\$ 95.85$. 1 hockey stick costs $\$ 30$. How much does 1 hockey puck cost?

2. An airline charges $\$ 153$ for each first-class ticket and $\$ 101$ for each coach ticket. There will be 139 passengers total. If $30 \%$ of the passengers composed fly first-class, how much money will the airline make?

3. John bought 6 shirts for his wife. For every shift he purchased, he got one for $30 \%$ off. If the normal price per shirt was $\$ 20$, how much money did John spend on his shopping trip?

4. Megan's sister is turning 48 in April. She is 3 times older than Megan's brother, John, and twice as old as Megan. How old is John?

5. Stacey and her husband have 77 books in their home library. Each of them bought the same number of books to add to their library this weekend at garage sales. They now have 91 books. How many books did they each buy?

6. After paying $\$ 9$ for a piece of pie for herself and her boyfriend, Jennifer has $\$ 55$ dollars left. How many more pieces of pie could she buy with this money?

7. Paul and his wife had 11 peaches left at their roadside fruit stand. They went to the orchard and picked more peaches to stock up for the afternoon crowd. They now have 172 peaches. How many did they pick?

8. There are 31 walnut trees currently in the park. Park workers will plant more trees Monday, Tuesday, and Wednesday this week. When workers are finished, there will be 94 trees. If they plant the same number of trees each day, how many will they plant on Monday?

9. Joy is baking a cake. The recipe calls for 1 and $1 / 4$ cups of sugar. If she has added $2 / 3$ cup, how much more does she need to add?

10. Brooke traveled to Houston by car to visit her husband's family. Going there took 9 hours, and the return trip lasted 5 hours. Brooke averaged a speed of 88 miles per hour returning. What was the average speed on the way there? 
APPENDIX F: TABLES

Table 1.

Means, Standard Deviations, and Measures of Normality for LGB-KASH and SJS

\begin{tabular}{lccccc}
\hline & $n$ & $M$ & $S D$ & Skewness & Kurtosis \\
\hline Pretest & & & & & \\
LGB-KASH Hate & 147 & 1.25 & 0.39 & 1.47 & 0.9 \\
LGB-KASH Rights & 147 & 5.41 & 0.82 & -1.45 & 1.45 \\
SJS Attitudes & 147 & 6.25 & 0.84 & -1.75 & 4.41 \\
& & & & & \\
Posttest & & & & & \\
LGB-KASH Hate & 147 & 1.27 & 0.47 & 2.42 & 7.34 \\
LGB-KASH Rights & 147 & 5.42 & 0.86 & -1.71 & 2.72 \\
SJS Attitudes & 147 & 6.35 & 0.81 & -1.88 & 5.11 \\
\hline
\end{tabular}

Note. DUREL = Duke University Religion Index; LGB-KASH = Lesbian, Gay, Bisexual

Knowledge and Attitudes Scale for Heterosexuals; SJS = Social Justice Scale

Table 2.

Independent Samples T-Tests for Dependent Variableson Preest Measures

\begin{tabular}{lccc}
\hline & $t$ & $d f$ & $p$ \\
\hline LGB-KASH Hate & -0.45 & 145 & 0.66 \\
LGB-KASH Rights & -0.67 & 145 & 0.51 \\
SJS Attitudes & -0.72 & 145 & 0.47 \\
\hline
\end{tabular}

Note. LGB-KASH = Lesbian, Gay, Bisexual Knowledge and Attitudes Scale for Heterosexuals;

SJS = Social Justice Scale

Table 3.

Correlations Between LGB-KASH Subscales, SJS Subscales, and DUREL Subscale Subscale

12

23

345

5

1. Hate Pretest

2. Rights Pretest

$-.52 * *$

3. Attitudes Pretest

$-.53 * * \quad .49 * *$

4. Hate Posttest

$.61 * * \quad-.43 * * \quad-.59 * *$

5. Rights Posttest

$\begin{array}{llll}-.48 * * & .75 * * & .42 * * & -.38 * *\end{array}$

6. Attitudes Posttest

$-.39 * * \quad .36 * *$

$.77 * * \quad-.40 * *$

$-.37 * * \quad-.14$

$.14 \quad-.41^{* *}$ $-.08$

Note. LGB-KASH = Lesbian, Gay, Bisexual Knowledge and Attitudes Scale for Heterosexuals; SJS = Social Justice Scale 
Table 4.

RM-ANOVA Within Subjects Main and Interaction Effects for LGB-KASH Hate Subscale

\begin{tabular}{lccc}
\hline Source & $d f$ & $F$ & $p$ \\
\hline Time & 1 & 0.16 & 0.69 \\
Time X Condition & 1 & 0.15 & 0.70 \\
Time X Condition X Gender & 1 & 2.99 & 0.09 \\
Error & 143 & & \\
& & & 0.08 \\
Time & 1 & 3.15 & 0.75 \\
Time X Condition & 1 & 0.11 & 0.55 \\
Time X Condition X Greek & 1 & 0.35 & \\
Error & 143 & & 0.57 \\
& & & 0.57 \\
Time & 1 & 0.14 & 0.20 \\
Time X Condition & 1 & 0.32 & \\
Time X Condition X Political & 1 & 1.66 & \\
Error & 143 & & 0.63 \\
Time & & & 0.38 \\
Time X Condition & 1 & 0.23 & 0.41 \\
Time X Condition X Religiosity & 1 & 0.79 & \\
Error & 1 & 0.70 & \\
\hline Note. $L B-K A S H$ & 143 & & \\
\end{tabular}

Note. LGB-KASH = Lesbian, Gay, Bisexual Knowledge and Attitudes Scale for Heterosexuals 
Table 5.

RM-ANOVA Within Subjects Main and Interaction Effects for LGB-KASH Rights Subscale

\begin{tabular}{lccc}
\hline Source & $d f$ & $F$ & $p$ \\
\hline Time & 1 & 0.00 & 0.96 \\
Time X Condition & 1 & 0.51 & 0.48 \\
Time X Condition X Gender & 1 & 0.70 & 0.40 \\
Error & 143 & & \\
& & & \\
Time & 1 & 0.01 & 0.94 \\
Time X Condition & 1 & 0.09 & 0.77 \\
Time X Condition X Greek & 1 & 0.00 & 0.98 \\
Error & 143 & & \\
& & & \\
Time & 1 & 0.02 & 0.89 \\
Time X Condition & 1 & 0.12 & 0.73 \\
Time X Condition X Political & 1 & 0.00 & 1.00 \\
Error & 143 & & \\
& & & \\
Time & 1 & 0.02 & 0.90 \\
Time X Condition & 1 & 0.16 & 0.69 \\
Time X Condition X Religiosity & 1 & 0.01 & 0.91 \\
Error & 143 & & \\
\hline Note. $L B-K A S H$ & 143
\end{tabular}

Note. LGB-KASH = Lesbian, Gay, Bisexual Knowledge and Attitudes Scale for Heterosexuals 
Table 6.

RM-ANOVA Within Subjects Effects for SJS

\begin{tabular}{lccc}
\hline Source & $d f$ & $F$ & $p$ \\
\hline Time & 1 & 2.37 & 0.13 \\
Time X Condition & 1 & 0.00 & 0.98 \\
Time X Condition X Gender & 1 & 1.43 & 0.23 \\
Error & 143 & & \\
& & & 0.06 \\
Time & 1 & 3.57 & 0.71 \\
Time X Condition & 1 & 0.14 & 0.69 \\
Time X Condition X Greek & 1 & 0.16 & \\
Error & 143 & & 0.06 \\
& & & 0.41 \\
Time & 1 & 3.67 & 0.57 \\
Time X Condition & 1 & 0.69 & \\
Time X Condition X Political & 1 & 0.33 & \\
Error & 143 & & 0.03 \\
& & & 0.49 \\
Time & 1 & 4.80 & 0.99 \\
Time X Condition & 1 & 0.48 & \\
Time X Condition X Religiosity & 1 & 0.00 & \\
Error & 143 & & \\
\hline Note. SUS Social & & & \\
\end{tabular}

Note. SJS = Social Justice Scale 